Air ions in boreal forest air

U. Hõrrak et al.

\title{
Characterization of air ions in boreal forest air during BIOFOR III campaign
}

\section{U. Hõrrak ${ }^{1,2}$, P. P. Aalto ${ }^{2}$, J. Salm ${ }^{1}$, J. M. Mäkelä ${ }^{3}$, L. Laakso ${ }^{2}$, and M. Kulmala ${ }^{2}$}

${ }^{1}$ Institute of Environmental Physics, University of Tartu, 18 Ülikooli St., 50090 Tartu, Estonia

${ }^{2}$ Department of Physical Sciences, Division of Atmospheric Sciences P.O. Box 64, FIN-00014 University of Helsinki, Finland

${ }^{3}$ Tampere University of Technology, Institute of Physics, P.O. Box 692, FIN-33101, Tampere, Finland

Received: 26 January 2005 - Accepted: 14 March 2005 - Published: 4 May 2005

Correspondence to: U. Hõrrak (urmas.horrak@ut.ee)

(c) 2005 Author(s). This work is licensed under a Creative Commons License.
Title Page

Abstract Introduction

Conclusions

References

Tables

Figures

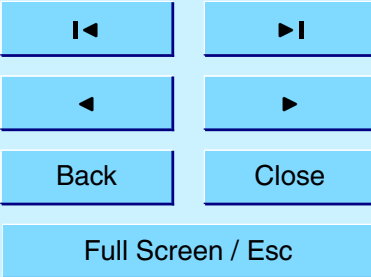

Print Version

Interactive Discussion 


\section{Abstract}

The behavior of the concentration of positive small (or cluster) air ions and naturally charged nanometer aerosol particles (aerosol ions) has been studied on the basis of measurements carried out in a boreal forest at the Hyytiälä SMEAR station, Finland,

during the BIOFOR III campaign in spring 1999. Statistical characteristics of the concentrations of cluster ions, two classes of aerosol ions of the sizes of $2.5-8 \mathrm{~nm}$ and $8-$ ca $20 \mathrm{~nm}$ and the quantities that determine the balance of small ions in the atmosphere have been given for the nucleation event days and non-event days. The dependence of small ion concentration on the ion loss (sink) due to aerosol particles was investigated ion concentration and the ion sink were closely correlated (correlation coefficient $87 \%$ ) when the fog events and the hours of high relative humidity (above 97\%), as well as nocturnal calms and weak wind (wind speed $<0.6 \mathrm{~m} \mathrm{~s}^{-1}$ ) had been excluded. In the case of nucleation burst events, variations in the concentration of small positive ions were in accordance with the changes caused by the ion sink due to aerosols; no clear indication of positive ion depletion by ion-induced nucleation was found. The estimated average ionization rate of air at the Hyytiälä station in early spring, when the ground was partly covered with snow, was about 4.8 ion pairs $\mathrm{cm}^{-3} \mathrm{~s}^{-1}$. The study of the charging state of nanometer aerosol particles $(2.5-8 \mathrm{~nm})$ revealed a strong correlation (correlation coefficient $88 \%$ ) between the concentrations of particles and their charged fraction (positive air ions) during nucleation bursts. The estimated charged fraction of particles, which varied from $3 \%$ to $6 \%$ considering various nucleation event days, confirms that these particles are almost quasi-steady state charged. Also the particles and air ions in the size range of $8-\mathrm{ca} 20 \mathrm{~nm}$ showed a good qualitative consistency;

\section{ACPD}

$5,2749-2790,2005$

Air ions in boreal forest air

U. Hõrrak et al.

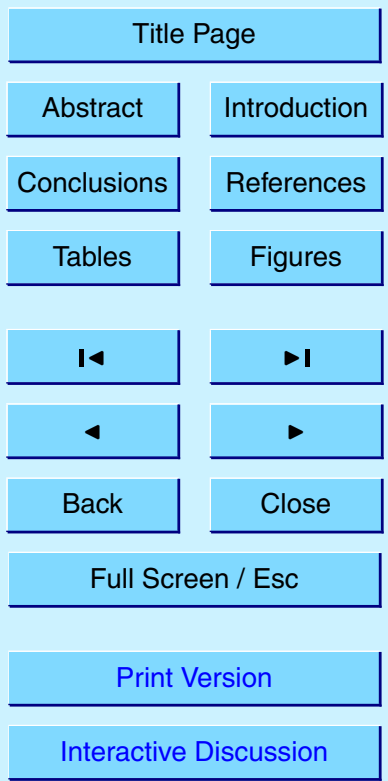

EGU 


\section{Introduction}

The formation and growth of ultrafine aerosol particles in the atmosphere have been studied during the last decade at many different locations around the world because of their possible impact on the radiation balance and thereby on the climate of the Earth

5 (Kulmala et al., 2004a; Birmili et al., 2003; Tunved et al., 2003). Various theories have been elaborated to explain the mechanisms of new particle generation (e.g. Raes and Janssens, 1985; Yu and Turco, 2000, 2001; Laakso et al., 2002; Korhonen et al., 1999; Kulmala et al., 2000; Napari et al., 2002). Despite the frequently observed particle formation events, the microphysical mechanisms of nucleation have remained unclear because of the very small size of newly born particles (about $1-2 \mathrm{~nm}$ ). This size range is not within the scale of modern aerosol instruments using artificial charging of particles. Air ion spectrometers are suitable to measure naturally charged clusters and particles down to about $0.4 \mathrm{~nm}$, but the charging state of newly born particles is not known in the atmosphere (due to different particle formation mechanisms). Experimental study of 15 new particle formation in the atmosphere is complicated also because the size range of new particles coincides with the size range of cluster ions $(0.4-1.6 \mathrm{~nm})$. The knowledge about the behaviour of ion clusters, particles and their charged fraction (air ions) during nucleation events could contribute to elucidate the role of different nucleation mechanisms.

20 The importance of air ions in the particle formation processes has been shown in several laboratory experiments (Ramamurthi et al., 1993; Kim et al., 1997, 1998; Hanson and Eisele, 2002; Froyd and Lovejoy, 2003a, b; Wilhelm et al., 2004). Comprehensive overviews about the charging and charge distribution on aerosol particles in a bipolar ion environment can be found in (Hoppel and Frick, 1986; Reischl et al., 1996).

According to laboratory experiments and theoretical considerations, the steady state charge distribution on large aerosol particles determined by the diffusion of small ions to particles is close to the Boltzmann distribution. Corrections have been found to be necessary in the case of ultrafine particles below $100 \mathrm{~nm}$ (Fuchs and Sutugin, 1971;

ACPD

$5,2749-2790,2005$

Air ions in boreal forest air

U. Hõrrak et al.

Title Page

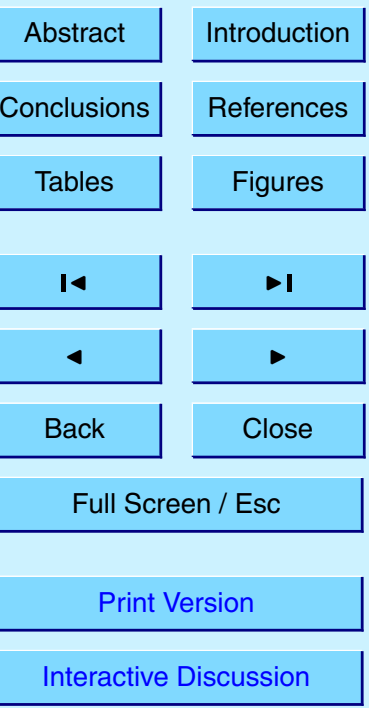

EGU 
Hoppel and Frick, 1986; Tammet, 1991; Reischl et al., 1996). However, only few experimental studies on the subject have been carried out in the real atmosphere. So far, the problems of the bursts of intermediate ions (generation of charged nanometer aerosol particles) and of the charge distribution on freshly nucleated atmospheric nanoparticles 5 have been briefly discussed (Hõrrak et al., 1998a, b, 2003a, b; Mäkelä et al., 2001a, 2003; Tamm et al., 2001). An extensive study of air ions and aerosol particles was recently conducted in a boreal forest at the Hyytiälä SMEAR station, Finland, during the QUEST campaign (21 March-10 April 2003) (Kulmala et al., 2004b; Laakso et al., 2004a, b).

10 The objective of this work was a comparative study of air ions (naturally charged small or cluster ions and aerosol particles) and fine aerosol particles with the main focus on the balance between small ions and aerosols, as well as on the charging state of nanometer particles during nucleation events. Simultaneous measurements of the concentration of cluster ions and the size distribution of aerosol particles enable to

15 estimate also the ionization rate of the air (or ion production rate), which is a key factor in ion-induced nucleation.

\section{Measurements}

Atmospheric aerosols and the concentration of air ion mobility classes were measured in a boreal forest at the Hyytiälä SMEAR station, Finland, during the BIOFOR III cam20 paign (31 March-29 April 1999) (Kulmala et al., 2001a; Aalto et al., 2001). Aerosol particle size distribution was measured by means of a dual DMPS (Differential Mobility Particle Sizer) system covering sizes of $3-500 \mathrm{~nm}$. The devices had a Hauketype differential mobility analyzer (DMA), a closed loop sheath flow arrangement and a Krypton-85 aerosol neutralizer. For large particles, an aerodynamical particle sizer 25 (APS, TSI model 3320) was used to measure the size distribution from $0.7 \mu \mathrm{m}$ up to $20 \mu \mathrm{m}$. This instrument was located in a truck about $40 \mathrm{~m}$ from the cottage where the DMPS system had been installed. Both instruments had sampling lines of the 2-m
ACPD

$5,2749-2790,2005$

\section{Air ions in boreal} forest air

U. Hõrrak et al.

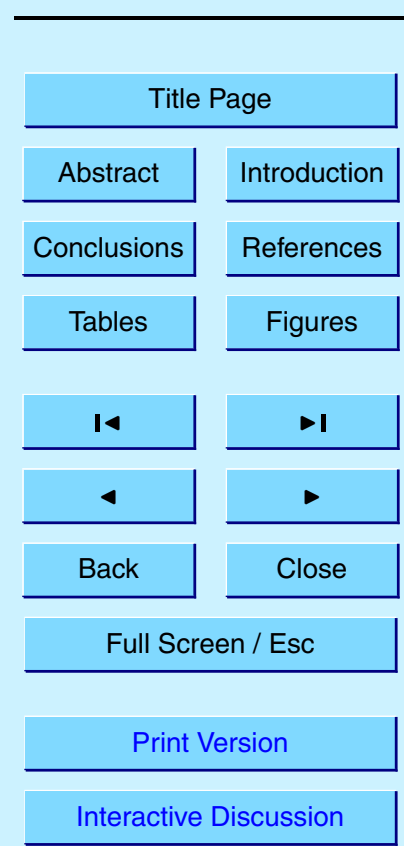

EGU 
level inside the forest. The sample flow and sheath flow of the DMPS, as well as the sample flow of the APS were not dried. However, the size distributions of particles measured by means of both devices can be considered as "dry size distributions" due to low relative humidity inside the instruments (especially in APS). Additional informa5 tion about the accumulation mode and coarse mode particles in the diameter range of $0.2-32 \mu \mathrm{m}$ was obtained using in-situ optical particle counters: a Particle Measuring System's (PMS) Active Scattering Aerosol Spectrometer Probe (ASASP-300) and a Classical Scattering Aerosol Spectrometer Probe (CASAP-100) covering the sizes above $0.5 \mu \mathrm{m}$ (Kulmala et al., 2001a; Hämeri et al., 2001). The optical counters sam10 pled wet-ambient aerosol particles on a mast at a height of about $18 \mathrm{~m}$ above the ground.

In order to estimate the concentration of air ions in different mobility classes, four integral ion counters UT8401 were applied (Aalto et al., 2001). The concentrations of positive small or cluster ions (Stokes-Millikan mobility equivalent diameter less than $152.5 \mathrm{~nm}$ ) and two classes of aerosol ions - charged fine nanometer particles $(2.5-8 \mathrm{~nm})$ and coarse nanometer particles (8-ca $20 \mathrm{~nm}$ ) - were derived. Air ions were measured as naturally charged in the bipolar atmospheric air. Due to the nature of the integral ion counter, the fraction concentrations can be calculated by means of a special inversion algorithm (Tammet, 1970). The upper boundary of $20 \mathrm{~nm}$ cannot be exactly determined because of the contribution of charged aerosol particles of larger sizes: the larger the particle, the smaller is its contribution to signal. The sampling height of ion counters was $2 \mathrm{~m}$ above the ground; the data were recorded every $10 \mathrm{~min}$. The distance between the measurement locations of air ions and aerosols was about $450 \mathrm{~m}$. For details about the instrumentation see (Kulmala et al., 2001a; Aalto et al., 2001).

The average temperature in the first half of April was $2.2^{\circ} \mathrm{C}$ and in the second half $7.0^{\circ} \mathrm{C}$. The depth of the snow cover was about $40 \mathrm{~cm}$ at the beginning and $20 \mathrm{~cm}$ in the middle of April; the snow cover melted quickly during the week after 15 April 1999.
ACPD

5, 2749-2790, 2005

\section{Air ions in boreal forest air}

U. Hõrrak et al.

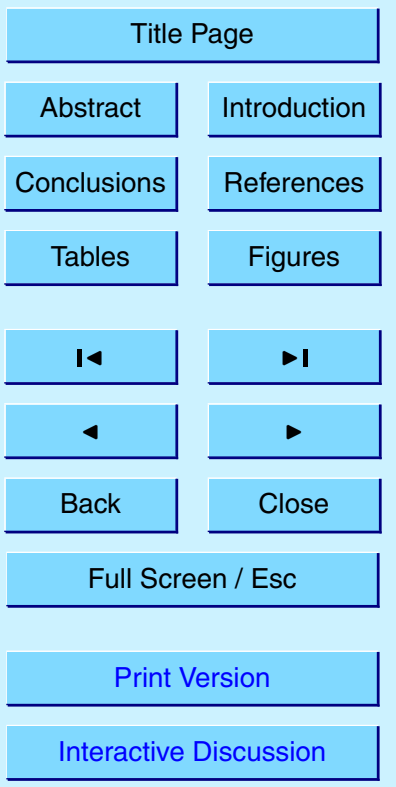

EGU 


\section{Theoretical background}

3.1. The balance of ions in the atmosphere

Small positive and negative ions are generated in the atmosphere mainly by cosmic radiation and natural radioactivity. Two concurrent processes, ion-ion recombination 5 and adsorption of small ions by aerosol particles, are responsible for the loss of small ions. The simplified balance equation of small ions in a bipolar environment, considering equal numbers of positive and negative small ions and symmetrical charging of aerosol particles, can be written as (Hoppel and Frick, 1986)

$\frac{d n}{d t}=q-\alpha n^{2}-\beta_{e f f} N_{t o t} n$,

10 where $q$ is the ionization rate, $\alpha$ is the recombination coefficient, $n$ is the concentration of small ions, $N_{\text {tot }}$ is the total concentration of aerosol particles, and $\beta_{\text {eff }}$ is the effective ion-aerosol attachment coefficient for polydisperse aerosol particles. The time constant of the transfer to steady state condition $(d n / d t=0)$ is about $1 \mathrm{~min}$ in the continental boundary layer air. This balance equation does not take into account the loss of small ions by ion-induced nucleation due to its complicated nature. The simplified balance equation of small ions has an analytical steady state solution:

$$
n=\frac{2 q}{\beta_{e f f} N_{t o t}+\sqrt{\beta_{e f f}^{2} N_{t o t}^{2}+4 \alpha q}}
$$

It can also be presented in the form: $n=q \tau$, where the parameter $\tau$ has the dimension of time and can therefore be interpreted as the "mean lifetime" of small ions in steady state conditions (Israël, 1970). The mean lifetime of small ions is inversely proportional to the total ion loss caused by ion-aerosol attachment and by the recombination of small ions.

The independent parameters of the balance equation have the following average values often cited in publications. The recombination coefficient $\alpha$, which depends on 2754

\section{ACPD}

$5,2749-2790,2005$

\section{Air ions in boreal forest air}

U. Hõrrak et al.

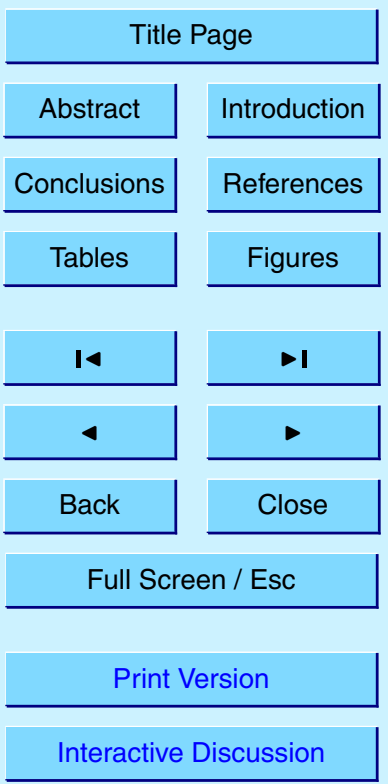

EGU 
the nature of small ions and the properties of the environment (Israël, 1970; Hoppel and Frick, 1986), has an average value of about $1.5 \cdot 10^{-6} \mathrm{~cm}^{3} \mathrm{~s}^{-1}$. In continental areas the parameter $\beta_{\text {eff }}$ varies in the range of (1-2) $10^{-6} \mathrm{~cm}^{3} \mathrm{~s}^{-1}$, depending on the size distribution of aerosol particles (Hoppel, 1985). The average ionization rate near the 5 ground of about 10 ion pairs $\mathrm{cm}^{-3} \mathrm{~s}^{-1}$ (caused by radioactive substances in the ground and in the air, and by cosmic radiation) is considered as an avarage for continental areas.

The "ion sink" due to aerosols is given by the equation (Hoppel and Frick, 1986; Tammet, 1991):

$S_{a}=\beta_{e f f} N_{t o t}=\int_{r} \sum_{i=-\infty}^{\infty} \beta_{i}(r) p_{i}(r) n(r) d r$,

were $\beta_{i}(r)$ is the ion-aerosol attachment coefficient between small positive (or negative) ions and particles with radius $r$ and with $i$ (or $-i$ ) elementary charges, $p_{i}(r)$ is the probability of carrying $i$ elementary charges on a particle and $n(r)$ is the size distribution of aerosol particles.

The attachment of small ions to aerosol particles gives rise to a size-dependent statistical charge distribution on the aerosol particles (Hoppel and Frick, 1986; Reischl et al. 1996). The time in which the aerosol particle population approaches charge equilibrium depends on the collision rate between small ions and aerosol particles, and also on the particle formation mechanism (e.g. homogeneous nucleation, ion-induced aerosol particles, the time required to reach charge equilibrium is typically in the range of about $0.5-1 \mathrm{~h}$ (Hoppel, 1985). For rural areas, away from direct sources of aerosol particles, the assumption of charge equilibrium is presumed to be fairly good. However, the charge distribution on freshly nucleated nanometer particles needs further study.

\section{ACPD}

$5,2749-2790,2005$

Air ions in boreal forest air

U. Hõrrak et al.

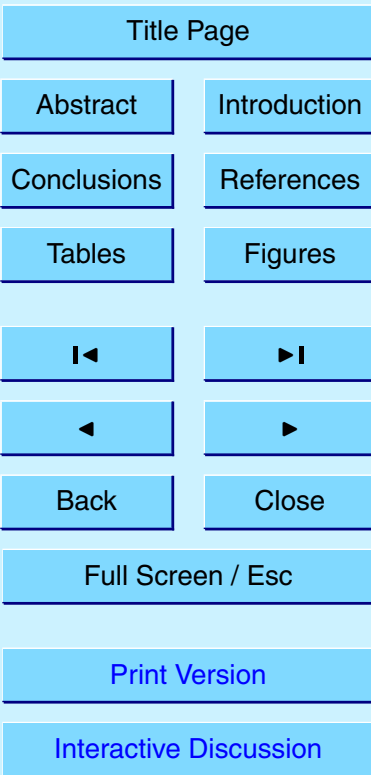

EGU 


\subsection{Calculation of ion sink}

The effect of atmospheric aerosols on the small ion concentration was estimated applying a simplified model of bipolar diffusion charging of aerosols (by small ions) and assuming the steady state conditions and symmetrical charging (Tammet, 1991; Hõrrak 5 et al., 1998b). The calculation of an ion sink is based on the model of ion-aerosol attachment (Hoppel and Frick, 1986, 1990). The charging probability $p_{i}(r)$ for the steady state is calculated using the algorithm given by Tammet (1991) with improvements described in (Hõrrak et al., 1998b). The model of charge distribution is based on the expression for the attachment coefficient of a small (cluster) ion to an aerosol particle:

$\beta_{i}(r)=\frac{4 \pi r k T Z}{e} \frac{x}{\exp (x)-1} \sqrt{1-\frac{2}{2+i(i-1)+r /(5 \mathrm{~nm})}}$,

where $Z$ is the mean mobility of cluster ions, $x=i e^{2} /\left(4 \pi r \varepsilon_{o} k T\right), \varepsilon_{O}$ is the electric constant, $k$ is the Boltzmann constant, and $T$ is the temperature.

The Eq. (4) approximates the tabulated results of Hoppel and Frick (1990) and is also in accordance with the experimental data of charging probabilities of nanometer aerosol particles (Reischl et al., 1996). The function $p_{i}(r)$ is defined by the equation:

$p_{i}(r)=\frac{N_{i}(r)}{1+2 \cdot \sum_{j=1}^{\infty} N_{j}(r)}$,

where $N_{i}(r)=\prod_{j=1}^{i} \beta_{j-1}(r) / \beta_{-j}(r)$ and the term $1+2 \cdot \sum_{j=1}^{\infty} N_{j}(r)$ denotes the total concentration of particles if $N_{0}(r)=1$. The equivalent, or the single size ion-aerosol attachment coefficient

$w(r)=\sum_{i=-\infty}^{\infty} \beta_{i}(r) p_{i}(r)$
ACPD

$5,2749-2790,2005$

Air ions in boreal forest air

U. Hõrrak et al.

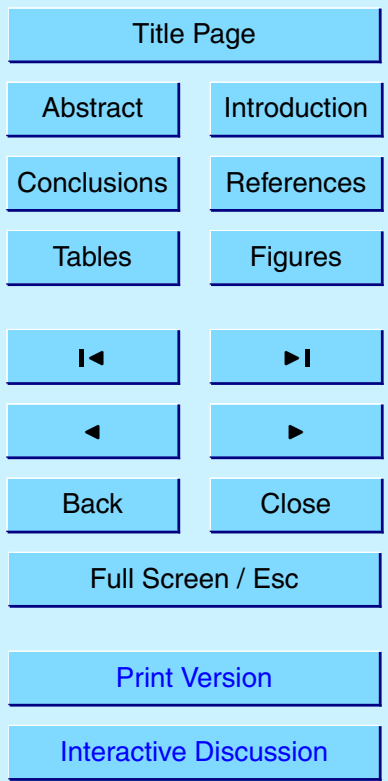

EGU 
in Eq. (3) is proportional to the particle diameter and, therefore, the ion sink $\left(\beta_{\text {eff }} Z_{\text {tot }}\right)$ can be interpreted as the diameter concentration of aerosol particles (Hoppel and Frick, 1986). A simple approximation function originates from Tammet (1991):

$w(r)=\sqrt{\frac{2 r-1 n m}{2 r+5 n m}} \frac{2 r}{40 n m} 10^{-6}$,

5 where the particle radius $(r)$ is in nanometers $(\mathrm{nm})$ and $w(r)$ is in $\mathrm{cm}^{3} \mathrm{~s}^{-1}$. Equation (7) was improved compared to (Tammet, 1991): the square root was added, which provides a better agreement with exact calculations by means of Eqs. (4), (5) and (6). The dependence of the single size ion-aerosol attachment coefficient on the particles of different sizes $(2 \mathrm{~nm}-10 \mu \mathrm{m})$ is shown in Fig. 1. The mean mobility of positive and neg10 ative cluster ions of $1.45 \mathrm{~cm}^{2} \mathrm{~V}^{-1} \mathrm{~s}^{-1}$, standard temperature $\left(20^{\circ} \mathrm{C}\right)$ and air pressure $(1013 \mathrm{mb})$ have been used in these calculations.

The depletion rate of small air ions due to aerosols (ion sink) is found by integrating over the size distribution of aerosol particles of 3-500 nm measured by means of the dual DMPS system. The effect of large particles above $500 \mathrm{~nm}$ was studied using 15 the data of the Aerodynamic Particle Sizer (APS). The particle size distributions in the diameter range of $0.72-20 \mu \mathrm{m}$ measured with the APS were converted to the mobility diameter by dividing the aerodynamic diameter by the square root of the estimated particle density of $1.9 \mathrm{~g} \mathrm{~cm}^{-3}$ (Aalto et al., 2001). The ion sink is closely correlated with the condensation sink (condensation rate of vapors on aerosol particles) (Kulmala et al., 2001b) because the both factors are mainly depending on the diameter concentration of aerosol particles (first moment of the size distribution).

Air ions in boreal forest air

U. Hõrrak et al.

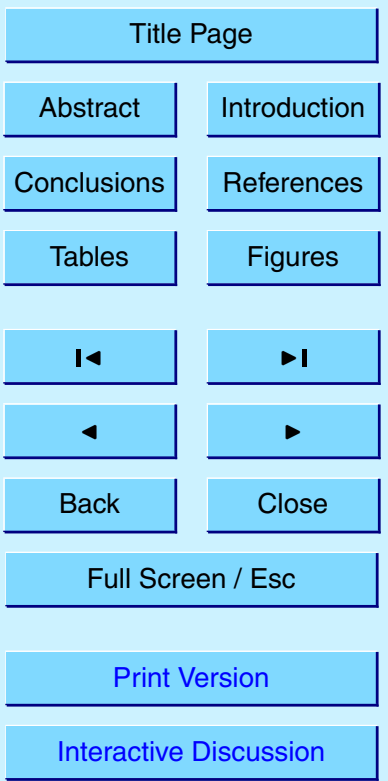

EGU 


\section{Results and discussion}

4.1. Statistical characterization of small air ions and ion loss

Statistical characteristics of the positive small (cluster) ion concentration, the sink of small ions on aerosol particles of $3-500 \mathrm{~nm}$ measured by the DMPS, as well as the 5 factors of the small ion balance Eq. (2) are presented in Table 1, separately for the nucleation event days and non-event days. The days have been classified as "nucleation event days" or "non-event days" according to the occurrence of new particle formation followed by the particle size distribution measurements. The classification given in Kulmala et al. (2001a) was used in the present study with one exception: the first half of 21

10 April, when polluted air masses were present, was excluded from the list of nucleation event days.

Considering all the measurements, the ion sink on aerosols varied in the range of $3.9 \cdot 10^{-4}-5.8 \cdot 10^{-2} \mathrm{~s}^{-1}$, commonly $10^{-3}-1.2 \cdot 10^{-2} \mathrm{~s}^{-1}$. The smallest values were recorded after the inflow of clean maritime air masses, while the highest values correspond to the polluted continental air masses, when the accumulation mode aerosol particles are mainly responsible for the ion sink. During the nucleation event days (13 days) the average ion sink was about 1.8 times smaller compared to non-event days, and the mean concentration of small ions was higher: $530 \mathrm{~cm}^{-3}$ versus $424 \mathrm{~cm}^{-3}$, respectively. The highest concentrations of small ions up to about $1200 \mathrm{~cm}^{-3}$ were recorded during nighttime calms. The high concentrations were probably caused by the accumulation of radon near the ground during temperature inversions (Porstendörfer, 1994; Penttinen et al., 2003), which can significantly affect the ionization rate of the air. In the nucleation event days the average diurnal variation of the small ion concentration displayed the maximum of about $625 \mathrm{~cm}^{-3}$ during nighttime at 22-23 LST, 25 and the minimum of $460 \mathrm{~cm}^{-3}$ in the morning at 7-8 LST. The secondary maximum of $580 \mathrm{~cm}^{-3}$, which appeared at noon $(11: 30 \mathrm{LST})$, was correlated with the minimum in the ion sink of $2.6 \cdot 10^{-3} \mathrm{~s}^{-1}$ (the maximum of ion sink of $5.2 \cdot 10^{-3} \mathrm{~s}^{-1}$ appeared at 24 LST). The secondary maximum of small ions took place before the intensive gener-

\section{8}

ACPD

5, 2749-2790, 2005

Air ions in boreal forest air

U. Hõrrak et al.

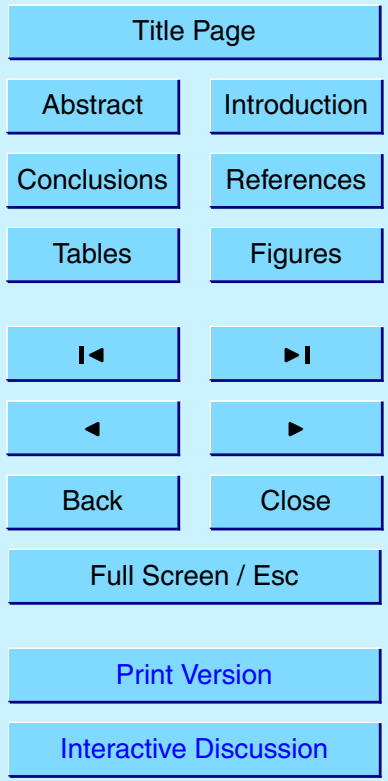

EGU 
ation of nanometer particles, it preceded the maximum of the average diurnal variation of $3 \mathrm{~nm}$ particles by about $1 \mathrm{~h}$. In general, the small ions measured at Hyytiälä showed the same regularities, but the concentrations were about two times higher than at the Tahkuse Observatory, Estonia (Hõrrak et al., 2000, 2003b).

5 It is worth to point out that at the Hyytiälä station, the loss of small ions due to ion-ion recombination (assuming the recombination coefficient $1.5 \cdot 10^{-6} \mathrm{~cm}^{3} \mathrm{~s}^{-1}$ ) was about $16 \%$ of the total ion loss due to small ion recombination and attachment to the aerosol particles, in average. Typically, it is less than $5 \%$ for continental areas (Tammet, 1991). In the case of very clean air, e.g. after the Arctic cold air advection from 10 the Northern Atlantic, the small ion recombination was responsible for about $70 \%$ of ion losses (Table 1). Here we neglected the effect of ion-induced nucleation on the loss of small ions. We also assumed an equal concentration of positive and negative small air ions; in general the ratio of positive to negative ions is about 1.12 (Hõrrak et al., 2000). The peak concentrations of small ions at Hyytiälä recorded in the very 5 clean air (about $800 \mathrm{~cm}^{-3}$ ) are still considerably smaller than the concentrations (up to $1200 \mathrm{~cm}^{-3}$ ) recorded during nocturnal calms (radon effect).

The sink of small ions at the Hyytiälä station was mainly determined by the concentration of particles in the size range of 3-500 nm measured by the DMPS; the contribution of larger particles measured by the APS (mobility equivalent diameter 0.52-15 $\mu \mathrm{m}$ ) was about two orders of magnitude smaller (see Fig. 2). For example, during the nucleation event days (non-event days) an average value of an ion sink measured by the APS was $4.88 \cdot 10^{-5} \mathrm{~s}^{-1}\left(11.47 \cdot 10^{-5} \mathrm{~s}^{-1}\right)$ and maximum was $14.5 \cdot 10^{-5} \mathrm{~s}^{-1}\left(49.6 \cdot 10^{-5} \mathrm{~s}^{-1}\right)$, respectively. The percentage contribution of particles in the size range of the APS was about $1.5 \%$ in average, and always less than $8 \%$. Therefore, if high accuracy is not essential when calculating the ion sink, then we can take into account only the DMPS measurements. However, the estimated ion sinks are probably to a certain extent underestimated because we did not take into account the hygroscopic growth of particle size due the effect of ambient humidity. During the BIOFOR campaign, Hämeri et al. (2001) studied the hygroscopic growth of aerosol particles in the dry particle di-
ACPD

$5,2749-2790,2005$

\section{Air ions in boreal forest air}

U. Hõrrak et al.

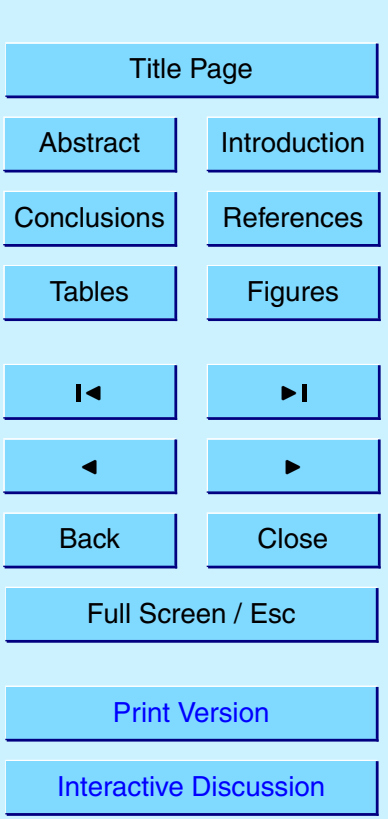

EGU 
ameter range of $0.01-2 \mu \mathrm{m}$ when taken from the dry state (relative humidity $\mathrm{RH}<5 \%$ ) to $\mathrm{RH}=90 \%$. The growth factors ranged between 1.0 and 1.6 considering particles of different sizes, and a clear diurnal variation of the growth factors of nucleation, Aitken and accumulation mode particles was found during nucleation event days.

The effective attachment coefficient, which is proportional to the mean diameter of aerosol particles, varied in the range of $2 \cdot 10^{-7}-3 \cdot 85 \cdot 10^{-6} \mathrm{~cm}^{3} \mathrm{~s}^{-1}$. These changes in the remote environment are affected by the long-range transport of aerosol pollutants and/or clean air advection, by the transformation of aerosol size distribution due to the evolution of boundary layer and new particle generation (Nilsson et al., 2001a, b). 10 During the nucleation burst days the effective attachment coefficient showed a considerable diurnal variation, on the average it varied from about $6 \cdot 10^{-7} \mathrm{~cm}^{3} \mathrm{~s}^{-1}$ up to $1.8 \cdot 10^{-6} \mathrm{~cm}^{3} \mathrm{~s}^{-1}$, displaying a nighttime maximum at about 4-5 LST and a minimum in the afternoon at 16 LST. During the peak time of nanometer particle generation by photochemical nucleation around noon, the effective attachment coefficient was almost 15 always less than $6 \cdot 10^{-7} \mathrm{~cm}^{3} \mathrm{~s}^{-1}$. The effective attachment coefficients found by Hoppel (1985) at the Naval Research Laboratory in urban Washington, D.C. were $1.15 \cdot 10^{-6}$ and $1.97 \cdot 10^{-6} \mathrm{~cm}^{3} \mathrm{~s}^{-1}$, and the ion sinks calculated from these measurements were $1.6 \cdot 10^{-2}$ and $4.64 \cdot 10^{-2} \mathrm{~s}^{-1}$ for the periods of good and poor visibility, respectively. Measurements in the marine environment near the east coast of the United States revealed 20 the attachment coefficients from $0.89 \cdot 10^{-6} \mathrm{~cm}^{3} \mathrm{~s}^{-1}$ up to $2.6310^{-6} \mathrm{~cm}^{3} \mathrm{~s}^{-1}$ and in the remote Atlantic as high as $3.18 \cdot 10^{-6} \mathrm{~cm}^{3} \mathrm{~s}^{-1}$. The corresponding ion sinks were in the range of $1.8 \cdot 10^{-2}-2.4 \cdot 10^{-2} \mathrm{~s}^{-1}$ and $6.46 \cdot 10^{-4} \mathrm{~s}^{-1}$, respectively. The effective attachment coefficients in considerably different environments are comparable with each other and with average values found in the boreal forest at Hyytiälä. The ion sink influenced by local air pollution, anthropogenic and natural sources of aerosols is a subject to considerable differences.

The average ionization rate of about 2.8 ion pairs $\mathrm{cm}^{-3} \mathrm{~s}^{-1}$, calculated from the balance Eq. (1) considering the steady state conditions, is too small for continental stations. It is probably underestimated by a factor of 2 . The average ionization rate at

ACPD

5, 2749-2790, 2005

\section{Air ions in boreal forest air}

U. Hõrrak et al.

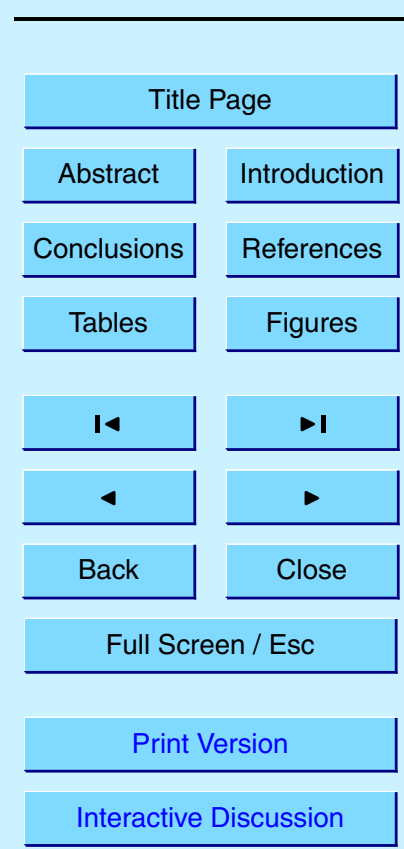

EGU 
$1 \mathrm{~m}$ height from the ground about 10 ion pairs $\mathrm{cm}^{-3} \mathrm{~s}^{-1}$ is considered as an average for continental areas (Israël, 1970, 1973; Chalmers, 1967). Three main ionizing agencies (factors) have the following contribution: the ionization rate caused by radioactive substances in the ground is about 4.6 ion pairs $\mathrm{cm}^{-3} \mathrm{~s}^{-1}$ and in the air (radon, radioac5 tive aerosol) 4 ion pairs $\mathrm{cm}^{-3} \mathrm{~s}^{-1}$, and by cosmic radiation 1.5-1.8 ion pairs $\mathrm{cm}^{-3} \mathrm{~s}^{-1}$. Considering different locations, the ionization rate could exhibit considerable variations depending on the content of radioactive substances in the ground, on the soil properties and due to local orography. The measurements below $1 \mathrm{~m}$ strongly depend on the ionization profile. The temporal variations in the ionization rate (annual and diurnal variation) are mostly due to variations in radon and thoron concentration in the air (Porstendörfer, 1994; Hoppel et al., 1986). Our estimates of the ionization rate did not take into account the loss of small ions by the deposition on the coniferous forest, which could affect the measurements at the Hyytiälä station, as well as the differences in the sizes of wet ambient particles and those sampled by the DMPS. Presumably the uncertainties of ion loss caused by these factors can explain the small values of ionization rate. The exceptionally high ionization rates found on 21 April with the nighttime maximum of 14.6 ion pairs $\mathrm{cm}^{-3} \mathrm{~s}^{-1}$ (Table $1 \mathrm{~b}$ ) are probably the artifacts caused by local air pollution, which did not affect the ion measurements. The most reasonable maximum value of the ionization rate estimated from the density distribution (excluding data of 21 20 April) is equal to that found for the nucleation event days, about 7.6 ion pairs $\mathrm{cm}^{-3} \mathrm{~s}^{-1}$. The average diurnal variation of the ionization rate displayed a moderate diurnal variation with the nighttime maximum of about 3.4 ion pairs $\mathrm{cm}^{-3} \mathrm{~s}^{-1}$ and the minimum of 2 ion pairs $\mathrm{cm}^{-3} \mathrm{~s}^{-1}$ in the afternoon.

Laakso et al. (2004a) applied the same approach to the calculation of the ionization 25 rate based on the measurements of the QUEST 2 campaign at the Hyytiälä station in spring 2003. The effect of the hygroscopic growth of the measured dry aerosol particle size distributions due to ambient humidity was also taken into account, but the average ionization rate stayed at a low value of 2.6 ion pairs $\mathrm{cm}^{-3} \mathrm{~s}^{-1}$.

The measurements at Hyytiälä show that the atmosphere always contains small air

ACPD

5, 2749-2790, 2005

Air ions in boreal forest air

U. Hõrrak et al.

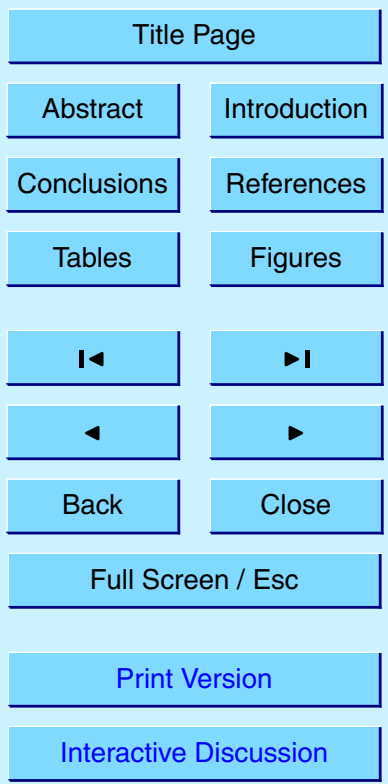

EGU 
ions that can act as condensation centers (of about $1 \mathrm{~nm}$ size) in the nucleation process. During intensive generation of nanometer aerosol particles the concentration of small ions was in the range of $380-780 \mathrm{~cm}^{-3}$, considering different event days. Therefore, when the homogeneous nucleation of new aerosol particles takes place in the 5 atmosphere, it should be accompanied by ion-induced nucleation (see e.g. Hoppel et al., 1994; Raes and Van Dingenen, 1992). To maintain the small ion population, the production rate of aerosols by ion-induced nucleation at the Hyytiälä station should be limited by the ionization rate (about 4-6 ion pairs $\mathrm{cm}^{-3} \mathrm{~s}^{-1}$ ) (Laakso et al., 2004a).

\subsection{Correlation between the concentration of small ions and ion sink}

10 The correlation between small ion concentration and the ion sink due to aerosol particles of the sizes of $3-500 \mathrm{~nm}$ is depicted in Fig. 3. The overall correlation is weak owing to the nighttime calms and weak wind, and due to high humidity periods (probably fog events) when the concentration of small ions varied independently of the ion sink. The fog is known to affect the conductivity of atmospheric air, reducing the concentration of small ions (Dolezalek, 1963; Hoppel et al., 1986). Contrary to that, the nighttime calms and weak wind favor the accumulation of radon near the ground, resulting in an increase in the ionization rate and, therefore, in the concentration of small ions up to about $1200 \mathrm{~cm}^{-3}$. Unfortunately, the radon concentration was not measured during the BIOFOR campaign. The accumulation of radon is confirmed by the measurements carried out at Hyytiälä during 2000-2003 (Penttinen et al., 2003). An alternative explanation of the occurrence of nighttime high concentrations proceeds from the hypothesis that the deposition rate of small ions on the coniferous forest is reduced in the case of weak wind and stable boundary layer, while the turbulent mixing can effectively enhance the deposition (Tammet and Kimmel, 1998; Tammet et al., 2001).

25 The fog events were identified comparing the data of the aerodynamical particle sizer (APS) and the optical aerosol spectrometer probes (ASASP-300 and CASAP100). The APS measures dry aerosol size distribution, while the optical probes sample wet-ambient particles in-situ at a high flow rate, thus providing measurements of hy-
ACPD

$5,2749-2790,2005$

Air ions in boreal forest air

U. Hõrrak et al.

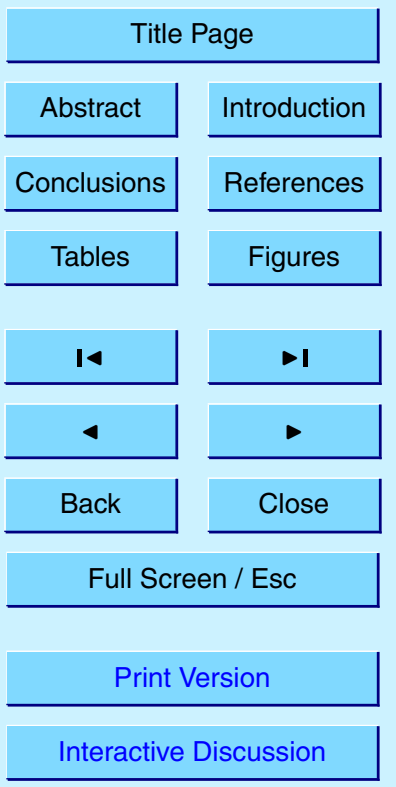

EGU 
drated aerosol size distributions affected by the ambient relative humidity. During high humidity (above 99\%), the size spectra were often completely different above the diameter of $0.5 \mu \mathrm{m}$, probably due to the presence of fog droplets, which are supposed to reside in the size range of $2-40 \mu \mathrm{m}$. We found an indication of fog during the nighttime 5 and/or early morning on 1, 2, 7, 15, 17 and 23 April. The effect of five fog events, when the ion counters were working properly and providing correct results, can be clearly seen in Fig. 3. The concentration of small ions had undergone a considerable decrease (deviation from the regression line), reaching values less than about $150 \mathrm{~cm}^{-3}$. These situations were correlated with fog events.

10 Another factor that could affect the concentration of small ions is precipitation (snow, sleet, rain). Precipitation can decrease the ionization rate due to the attenuation of gamma and beta radiation from the ground and due to the block of radon exhalation by the wet ground surface. Contrary to that, precipitation can also cause an increase in the ionization rate close to the ground due to the wet deposition of short-lived radioactive

daughters attached to aerosol particles (Hatakka et al., 1998). The effect of precipitation (snow, sleet, rain) was studied, but no clear direct or indirect effect on the concentration of small ions was found.

To find out a clear relationship between the concentration of small ions and the ion sink, we excluded the presumable fog events and also the hours of high humidity (more than $97 \%$ ), as well as the periods of weak wind (wind speed less than $0.6 \mathrm{~m} \mathrm{~s}^{-1}$ ) from the dataset. The results are depicted in Fig. 3b. In the case of the smallest ion sink of $3.9 \cdot 10^{-4} \mathrm{~s}^{-1}$, recorded after the inflow of clean maritime air masses from the North Atlantic (Mäkelä et al., 2001b), the concentration of small ions rose up to $800 \mathrm{~cm}^{-3}$, while during the polluted continental air masses (coming from Russia over St. Peters25 burg) with a considerably higher ion sink of $2.6 \cdot 10^{-2} \mathrm{~s}^{-1}$ the small ion concentration was diminishing down to $150 \mathrm{~cm}^{-3}$.

In accordance with the balance equation of small ions (2), if the ion sink is below about $10^{-3} \mathrm{~s}^{-1}$, the small ion concentration becomes nearly independent of that of aerosol particles approaching its limit in the case of aerosol free atmosphere. The
ACPD

$5,2749-2790,2005$

\section{Air ions in boreal forest air}

U. Hõrrak et al.

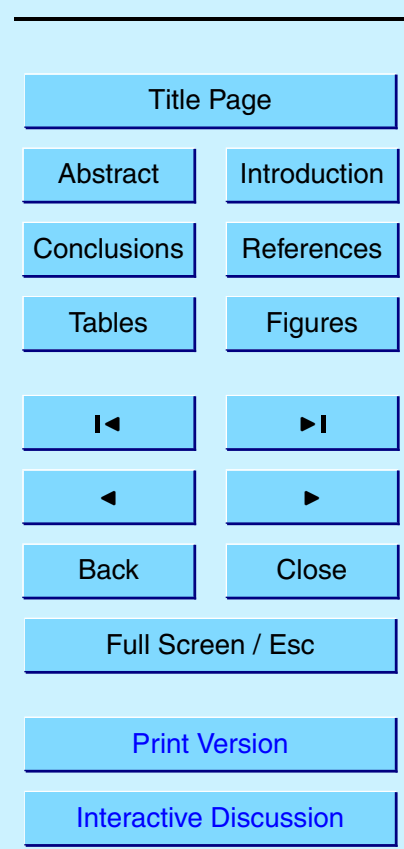

EGU 
concentration limits are about 1030,1830 or $2580 \mathrm{~cm}^{-3}$ if the ionization rate is $1.6,5$ or 10 ion pairs $\mathrm{cm}^{-3} \mathrm{~s}^{-1}$, respectively. The concentration limit of $1030 \mathrm{~cm}^{-3}$ best suits with our data, but the regression line in Fig. 3 is still far from the relationship predicted by Eq. (2), displaying significantly higher ion concentrations considering the ion sinks 5 above $10^{-3} \mathrm{~s}^{-1}$. The fact that the ionization rate of the air depends on the content of radioactive aerosols might only partially explain the discrepancy.

The correlation between the small ion concentration and the ion sink was stronger during the nucleation event days, because there were no fog events (except one, on 2 April) and relative humidity was considerably lower (average 62\%), compared with 10 the non-event days (average $82 \%$ ). If to take into account only the hours when the atmospheric boundary layer was well mixed (wind speed higher than $1 \mathrm{~m} \mathrm{~s}^{-1}$ ), then the nonlinear correlation coefficient was $92 \%$.

\subsection{Estimation of the ionization rate}

As discussed in the Sect. 4.1, the ionization rate derived from the balance equation of 15 small ions (Eq. 1) has unreasonably low values for continental stations: the average is about 2.8 ion pairs $\mathrm{cm}^{-3} \mathrm{~s}^{-1}$. Without any doubt we assume that the balance equation is valid, but the loss has been underestimated. However, the concentration of small ions and the ion sink were closely correlated (see Fig. 3b). Therefore we are looking for a constant extra ion loss, the addition of which can solve the discrepancy between the experimental data and the results derived from the balance equation. We applied a method of least squares to find out statistically grounded estimates of the free parameters of the balance equation: the ionization rate and a constant term of ion loss. To minimize the influence of local effects and fog events on the results, the periods of well-mixed atmospheric boundary layer were selected (wind speed $>1 \mathrm{~m} \mathrm{~s}^{-1}$, relative humidity $<97 \%$ ) for the data analysis. The results of the regression analysis are depicted in Fig. 4. The statistical estimate of the ionization rate is 4.8 ion pairs $\mathrm{cm}^{-3} \mathrm{~s}^{-1}$ and that of the additional constant ion loss is $5.2 \cdot 10^{-3} \mathrm{~s}^{-1}$. This extra ion loss, which is

ACPD

$5,2749-2790,2005$

Air ions in boreal forest air

U. Hõrrak et al.

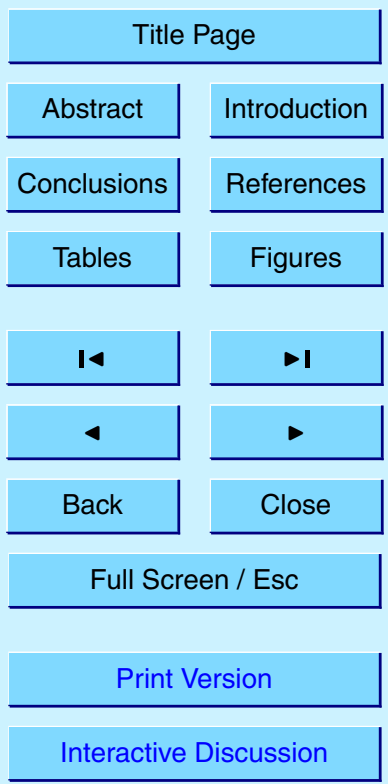

EGU 
approximately equal to the mean ion sink induced by aerosol particles of the sizes of 3-500 $\mathrm{nm}$, could be caused by the enhanced deposition of small ions on the coniferous forest. The ionization rate of 4.8 ion pairs $\mathrm{cm}^{-3} \mathrm{~s}^{-1}$ is typical for the continental stations of high latitude during the wintertime when the snow cover is present. The same 5 results were obtained when the hours when the wind speed is higher than $0.6 \mathrm{~m} \mathrm{~s}^{-1}$ and relative humidity is less than $97 \%$ were taken into account.

The estimated ionization rate of 4.8 ion pairs $\mathrm{cm}^{-3} \mathrm{~s}^{-1}$ fairly coincides with the value of 4.5 ion pairs $\mathrm{cm}^{-3} \mathrm{~s}^{-1}$ calculated for the same place from the external radiation and radon concentration measurements carried out during the QUEST 2 measurement 10 campaign in spring 2003 (Laakso et al., 2004a). Based on the results of the regression analysis, we can conclude that the ionization rate in Table 1 is systematically underestimated by about 2 ion pairs $\mathrm{cm}^{-3} \mathrm{~s}^{-1}$ and the ion loss of about $5.2 \cdot 10^{-3} \mathrm{~s}^{-1}$.

\subsection{Charging state of nanometer aerosol particles}

Simultaneous measurements of the concentrations of aerosol particles and naturally charged particles (air ions) in the atmosphere in the same size range enable to estimate the charged fraction or charging probability of particles. Considering the accuracy of nanometer particle measurements, it is possible to study the process only during the nucleation event days, when the enhanced concentrations of nanometer particles $\left(3-10 \mathrm{~nm}\right.$ ) up to about $12000 \mathrm{~cm}^{-3}$ (bursts) are observable in the size spectra in fine 20 weather conditions during the daytime.

To find the aerosol particle concentration in the size range coinciding with that of aerosol ions $m(2.5-8 \mathrm{~nm})$, we extrapolated the size distribution below $3 \mathrm{~nm}$. The upper boundary of the aerosol ion size class $N(8-\mathrm{ca} 20 \mathrm{~nm})$ is not exactly determined because of the applied method of air ion measurements by means of integral ion coun-

ters. Despite all, the analysis of the correlation between the concentrations of nanometer aerosol particles and their charged fraction (air ions) showed a good qualitative consistency in the case of the nucleation event days (Fig. 5). During the non-event days the concentrations of particles and air ions in the size class of $2.5-8 \mathrm{~nm}$ were
ACPD

$5,2749-2790,2005$

Air ions in boreal forest air

U. Hõrrak et al.

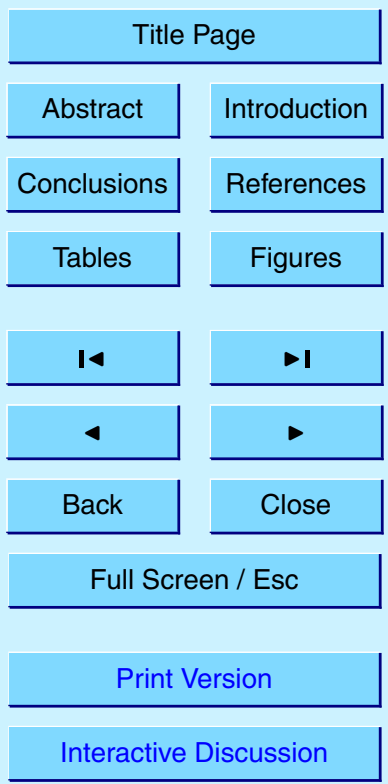

EGU 
close to low background (see Table 2), and the correlation was poor in general, while the particles and ions in the size class of $8-\mathrm{ca} 20 \mathrm{~nm}$ could show considerably higher concentrations and, therefore, also a stronger correlation (e.g. on 9 April the correlation coefficient was $95 \%$ ).

5 During the nucleation event days the enhancement of particle concentration in the size range of $2.5-8 \mathrm{~nm}$ precedes that in the size range of $8-20 \mathrm{~nm}$ as a consequence of particle growth toward large sizes. The average diurnal variation in the concentration of particles (and air ions) in the size class of $2.5-8 \mathrm{~nm}$ showed the maximum of $1910 \mathrm{~cm}^{-3}$ $\left(120 \mathrm{~cm}^{-3}\right)$ at noon $(12-13 \mathrm{LST})$, and in the size class of $8-20 \mathrm{~nm}$ about $3600 \mathrm{~cm}^{-3}$ $10\left(170 \mathrm{~cm}^{-3}\right)$ four hours later at $16-17$ LST. A wide minimum of particles (and ions) in the size class of $2.5-8 \mathrm{~nm}$ about $20-50 \mathrm{~cm}^{-3}\left(45-50 \mathrm{~cm}^{-3}\right)$ was recorded during the nighttime and early morning hours at 22-7 LST; the minimum of larger particles (and ions) about $300-400 \mathrm{~cm}^{-3}\left(45-50 \mathrm{~cm}^{-3}\right)$ took place in the early morning at 4-9 LST.

The correlation between the concentrations of aerosol particles and air ions in Fig. $5 a$ 15 is substantially affected by the nucleation burst on 5 April when the concentrations of nanometer particles $(2.5-8 \mathrm{~nm})$ up to $12030 \mathrm{~cm}^{-3}$ were recorded. Taking into account only the core of the scatterplot (data points below the particle concentration of about $5000 \mathrm{~cm}^{-3}$ ), the correlation coefficient decreases slightly from $87.6 \%$ down to $84.6 \%$, but the relationship (correlation curve) remains nearly the same. The coarse nanometer particles $(8-20 \mathrm{~nm})$ and their charged fraction in Fig. $5 \mathrm{~b}$ are even more strongly correlated compared to nanometer particles; the correlation coefficient is $92 \%$. Detailed information about the correlation coefficients for various nucleation days is presented in Table 3. The particle formation events in Table 3 have been classified into three classes according to the amount of generated new nanometer particles and the clear25 ness of the subsequent growth of particles from the nucleation mode up to the Aitken mode size range (Kulmala et al., 2001a; Mäkelä et al., 2000). The best ones were classified as class 1 . The events with the high concentration of background aerosol or non-continuous growth characteristics were classified as classes 2 or 3 . We found that the correlation between the concentrations of nanometer particles and air ions

ACPD

$5,2749-2790,2005$

\section{Air ions in boreal forest air}

U. Hõrrak et al.

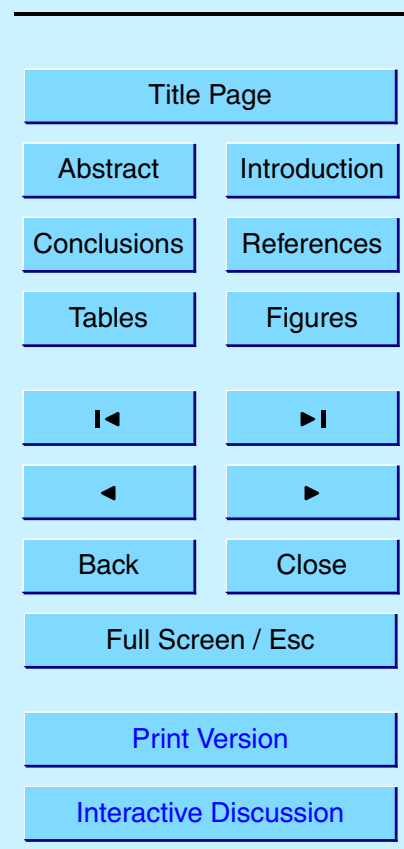

EGU 
was always linear during the nucleation bursts, considering different generation rates (followed by the maximum concentration of particles) and the growth rates of nanometer particles (Table 3). The event class 1 displayed the strongest correlation for the size class of 2.5-8 $\mathrm{nm}$, because the maximum concentrations of air ions are then well 5 above the background (about $40 \mathrm{~cm}^{-3}$ ). Based on these results we can conclude that the air ion measurements can give essential information about the basic regularities of the behavior of nanometer aerosol particles.

Since the size fractions of particles measured by means of ion counters and the DMPS were related one-to-one, then the scatterplot between the nanometer aerosol - particles and their charged fraction (air ions) could be fitted with a line of the linear regression function, the intercept of which should be zero, and the slope giving the mean charging probability for the fraction. The results of the regression analysis showed a linear correlation between the nanometer aerosol particles and their charged fraction, but with a non-zero intercept of about $20-60 \mathrm{~cm}^{-3}$. Probably this step at the zero value of the aerosol concentration (intercept) is due to methodological and instrumental uncertainties in the air ion fraction concentration estimation by means of integral ion counters (Tammet, 1970). This step in air ion concentration (average about 40$50 \mathrm{~cm}^{-3}$ ) was comparable, considering the size classes of $2.5-8 \mathrm{~nm}$ and 8-ca $20 \mathrm{~nm}$ during nucleation events or the non-event days. In this study we did not take into account the non-zero intercept and interpreted the slope of the linear regression line as an estimate of the mean charged fraction of particles (or experimental charging probability). The estimates of the positively charged fraction of nanometer aerosol particles $(2.5-8 \mathrm{~nm})$ given in Table 3 varied in the range of $3-6 \%$. The average of the most pronounced events of class 1 is about $4 \%$. These estimates are close to the steady state bipolar charging probability of $2.6 \%$ for the mean size of the fraction of $5.3 \mathrm{~nm}$ (Reischl et al., 1996). Considering the measurement accuracy, we cannot state that the excess of positively charged nanometer particles indicates to an overcharge of atmospheric aerosols due to the ion-induced nucleation. The charged fractions of coarse nanometer aerosol particles $(8-\mathrm{ca} 20 \mathrm{~nm}$ ) given in Table 3 are only the order of magni-
ACPD

5, 2749-2790, 2005

Air ions in boreal forest air

U. Hõrrak et al.

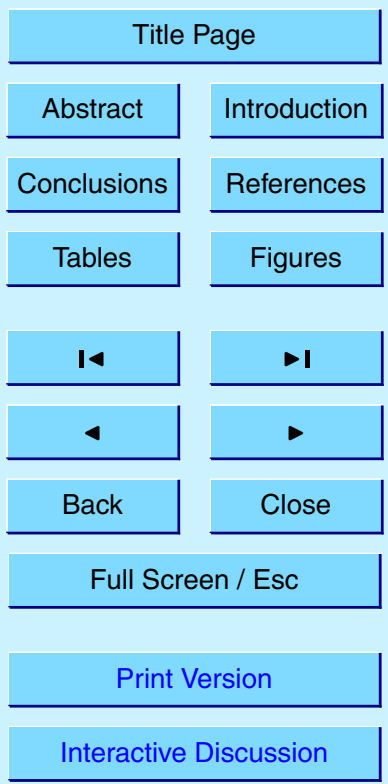

EGU 
tude estimates because of the uncertainty in the upper boundary of air ion size class. Despite that, it showed a nearly constant value, average about $4 \%$. The steady state bipolar charging probability for the mean size of the fraction of $12.7 \mathrm{~nm}$ should be about $7.2 \%$.

5 4.5. Case studies

Four nucleation event days were selected for the case studies to characterize the behavior of air ions of different classes: small ions and charged nanometer particles (Fig. 6). Some complementary information about the behavior of air ions and aerosol particles during these nucleation event days can be found in (Hõrrak et al., 2003a).

The diurnal variation in the concentration of small ions was different on different nucleation event days. On 2 April 1999 the data showed gradual increase in the concentration of small ions before the onset of the generation of nanometer aerosol particles at 12:30 LST. This is in general accordance with the decrease in the ion sink due to aerosol particles $\left(3-500 \mathrm{~nm}\right.$ ) from $(5-6) \cdot 10^{-3} \mathrm{~s}^{-1}$ during the nighttime down to the 15 minimum of $1.2 \cdot 10^{-3} \mathrm{~s}^{-1}$ in the afternoon (Fig. 7a). The ion sink stayed relatively constant (about 1.4.10 $10^{-3} \mathrm{~s}^{-1}$ ) during the intensive generation of nanometer particles. The increase in the ion sink caused by nanometer particles was compensated by the decrease in the concentration of the Aitken and accumulation mode particles. Therefore, no considerable changes in the concentration of small ions during the generation of nanometer aerosol particles can be found. The decrease followed the growth of new particles towards large sizes in the afternoon, when the particles in the size class of 8$20 \mathrm{~nm}$ displayed the concentration maximum. On 2 April the concentrations of nanometer aerosol particles $(2.5-8 \mathrm{~nm})$ and their charged fraction (aerosol ions) showed only a modest correlation (the correlation coefficient was $84 \%$ ), because a rise in the concentration of aerosol ions precedes (about $10 \mathrm{~min}$, or one measurement cycle) that of aerosol particles measured by the DMPS, probably due to spatial inhomogeneity of the nucleation process.

The peculiarity of this day (2 April) was the fog, which was detected by means of op-

ACPD

$5,2749-2790,2005$

Air ions in boreal forest air

U. Hõrrak et al.

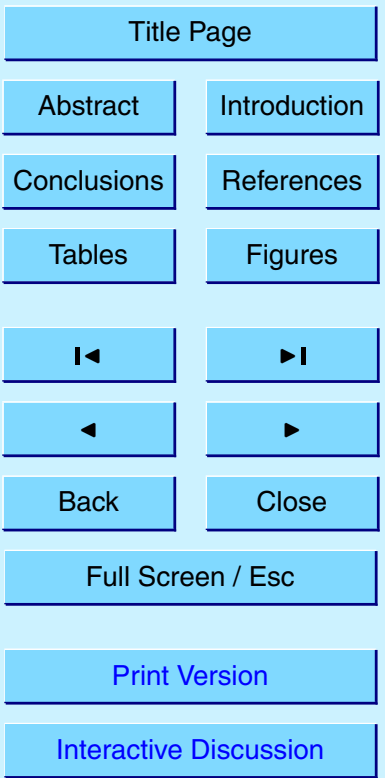

EGU 
tical spectrometers (ASASP-300, CASAP-100) during 2-7 LST in the morning with the maximum intensity around 4:50 a.m. The effect of the fog on the concentration of small ions is clearly visible in Fig. 7a, where the small ion concentration decreases independently of the ion sink (based on DMPS data) down to about $150 \mathrm{~cm}^{-3}$ around $4: 50$ a.m.

5 The scatterplot between the small ion concentration and the ion sink in Fig. 9a revealed a separate group below the concentration of about $300 \mathrm{~cm}^{-3}$. Presumably the fog affects all the data below the small ion concentration of about $300 \mathrm{~cm}^{-3}$. Another separate group of data with a relatively high concentration of small ions up to $710 \mathrm{~cm}^{-3}$, which corresponds to the nighttime weak winds less than $0.2 \mathrm{~m} \mathrm{~s}^{-1}$ is probably due to 10 the effect of radon on the ionization rate of the air. The nucleation event on 2 April 1999 was analyzed in detail by Aalto et al. (2001).

The next example in Fig. $6 c$ demonstrates the effect of clean air inflow on 10 April 1999. The increase in the concentration of small ions during the nighttime and early morning (up to $800 \mathrm{~cm}^{-3}$ ) followed the decrease in the ion sink from $5.5 \cdot 10^{-3} \mathrm{~s}^{-1}$ down 15 to $3.9 \cdot 10^{-4} \mathrm{~s}^{-1}$ at $6: 30$ LST. The ion sink was decreasing due to the inflow of clean maritime air mass from the North-Atlantic (Mäkelä et al., 2001b). The gradual increase in the ion sink after 6:30 LST up to $4 \cdot 1 \cdot 10^{-3} \mathrm{~s}^{-1}$ at 24 LST was caused by the local production of aerosols (Fig. 7b). The rise in the concentration of small ions in the evening after 18 LST was probably due to the accumulation of radon favored during the nighttime calm and weak wind; the wind speed was below $0.5 \mathrm{~ms}^{-1}$ and the temperature inversion developed after 19 LST. This separate group with the high concentration of small ions is clearly seen in the scatterplot of the small ion concentration versus the ion sink in Fig. 9c.

The characteristic feature of 10 April was that the concentration of small ions in the clean air (very small ion sink on aerosols) was mainly determined by small ion recombination. Ion-ion recombination was responsible for $75 \%$ of total ion loss at 6:30 LST. In the beginning of the burst of nanometer aerosol particles the ion-ion recombination was responsible for $40-55 \%$ of total ion loss (estimated by means of Eq. (1) considering the steady state condition and neglecting the effect of ion-induced nucleation).
ACPD

$5,2749-2790,2005$

\section{Air ions in boreal forest air}

U. Hõrrak et al.

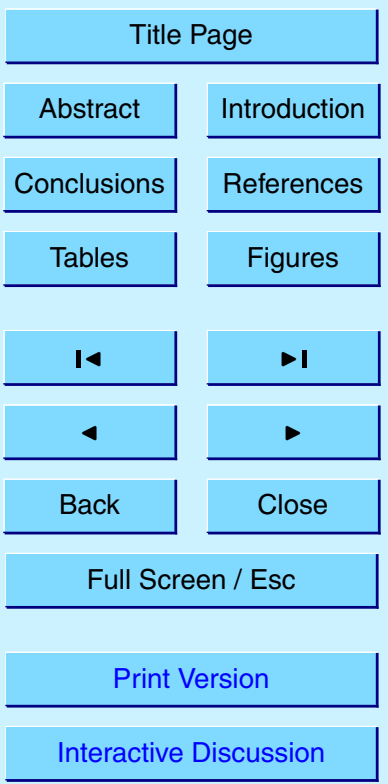

EGU 
During the other days selected for the case studies (on 2, 5 and 14 April) the maximum percentage of ion loss caused by small ion recombination was $44 \%, 30 \%$ and $20 \%$, respectively. Just before the burst of nanometer particles, these percentages were $27 \%$, $25 \%$ and $20 \%$, respectively. The hypothetical ion loss due to the enhanced deposition 5 of small ions on the coniferous forest discussed in Sect. 4.3 was not taken into account in these estimates.

5 and 14 April 1999 were the only days during the BIOFOR III campaign when the concentration of small (or cluster) ions was considerably decreasing during the nucleation burst (Figs. $6 b, d$ ). These days are of particular interest to the study of the 10 hypothetical role of ion-induced nucleation on the decrease of small ion concentration. The nucleation burst on 5 April was the most intensive in April with the peak concentration of nanometer particles $(2.5-8 \mathrm{~nm})$ of about $12000 \mathrm{~cm}^{-3}$, which is about two times higher than on other days. On 5 April, the minimum of the ion sink (about $2 \cdot 10^{-3} \mathrm{~s}^{-1}$ ) was recorded before the burst of nanometer particles at 9 LST (Fig. 8a). The decrease

in the concentration of small ions occurred simultaneously with a rapid increase in the concentration of aerosol ions $(2.5-8 \mathrm{~nm})$, as well as the concentration of nanometer aerosol particles recorded by the DMPS. The oscillation in the concentration of small ions after the nucleation burst was correlated with the changes in the ion sink induced by the concentration of coarse nanometer particles (8-ca $20 \mathrm{~nm}$ ) (Figs. 6b and 8a).

20 Also on 14 April, the ion sink displayed the minimum $\left(2.9 \cdot 10^{-3} \mathrm{~s}^{-1}\right)$ before the onset of the generation of nanometer particles at noon (12:20 LST) (Fig. 8b), the decrease of small ions followed after that. Similarly to the previous case (on 5 April), the concentrations of fine nanometer particles $(2.5-8 \mathrm{~nm})$ and coarse nanometer particles $(8-$ ca $20 \mathrm{~nm}$ ) started to increase almost simultaneously, afterwards displaying a delay in the peak concentrations about 30 min (Figs. $6 \mathrm{~b}$ and d). In general, the delay between the concentration maxima of two ion (or particle) classes, affected by the particle growth towards large sizes after the generation, was many times longer (about $3.5 \mathrm{~h}$ ). The growth rate of nanometer particles (in the size range of $3-10 \mathrm{~nm}$ ) on 5 and 14 April was comparatively high: 6.7 and $5.4 \mathrm{~nm} \mathrm{~h}^{-1}$, respectively (Table 3). The study
ACPD

$5,2749-2790,2005$

\section{Air ions in boreal forest air}

U. Hõrrak et al.

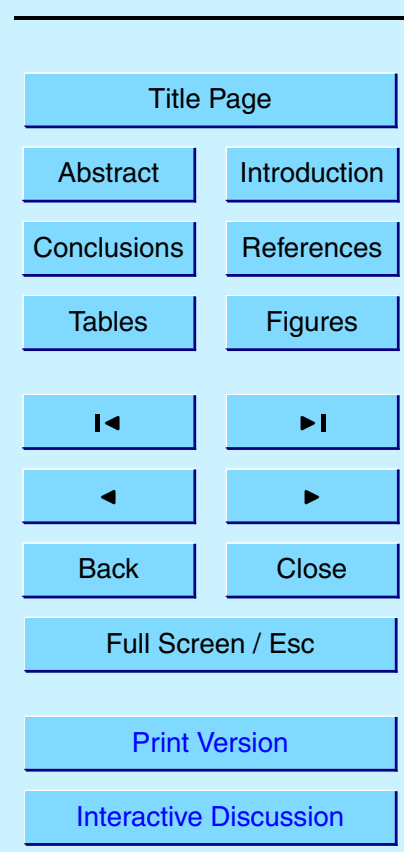

EGU 
of the evolution of the distribution of the ion sink on particle sizes on 5 and 14 April (Fig. 8) confirms that the decrease in the concentration of small ions was caused by an intensive generation of nanometer aerosol particles followed by a rapid growth of particles towards large sizes. The scavenging efficiency of small ions by aerosol particles in 5 the size class of $8-20 \mathrm{~nm}$ is about 3 times higher compared to the particles in the size class of $2.5-8 \mathrm{~nm}$. Thus, on both days the decrease in the small ion concentrations can be well explained by the effect of aerosols (Figs. 9b, d).

The nucleation events on both 5 and 14 April with a rapid increase in the concentration of charged fine nanometer particles $(2.5-8 \mathrm{~nm})$ and coarse nanometer particles $10 \quad(8-\mathrm{ca} 20 \mathrm{~nm})$ showed a good correlation between the nanometer aerosol particles and their charged fraction (positive air ions) (Table 3). Kulmala et al. (2001b) applied an analytical model and found that the formation rate of $3 \mathrm{~nm}$ particles was $1.6 \mathrm{~cm}^{-3} \mathrm{~s}^{-1}$ on 5 April and $1.1 \mathrm{~cm}^{-3} \mathrm{~s}^{-1}$ on 14 April. The estimated nucleation rates (generation rate of $1 \mathrm{~nm}$ particles) were $10-100 \mathrm{~cm}^{-3} \mathrm{~s}^{-1}$ and $50-80 \mathrm{~cm}^{-3} \mathrm{~s}^{-1}$, respectively.

As a result of the case studies, we can conclude that both the ion sink on aerosols and small ion recombination are essential factors of small ion loss in the comparatively clean air at Hyytiälä. If the nucleation burst of nanometer particles is able to cause changes in the ion sink by about $2 \cdot 10^{-3} \mathrm{~s}^{-1}$, then the effect is clearly observable in the concentration of small ions. This change in ion sink is significant considering the extent of its variation during nucleation event days (Fig. 9).

\section{Conclusions}

On the basis of the measurements carried out during the BIOFOR III campaign, we can point out the following characteristics of the behaviour of positive air ions at boreal forest in early spring.

25 The concentration of small (or cluster) ions at the Hyytiälä station varied from 110 to $1183 \mathrm{~cm}^{-3}$, the average was about $480 \mathrm{~cm}^{-3}$. The highest concentrations were recoded during the nighttime calms and after the inflow of clean maritime air masses.
ACPD

$5,2749-2790,2005$

\section{Air ions in boreal forest air}

U. Hõrrak et al.

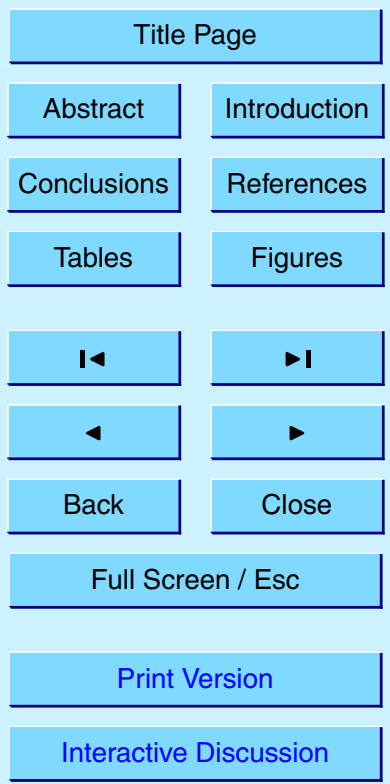

EGU 
The smallest concentrations below about $300 \mathrm{~cm}^{-3}$ belonged to fog events and polluted continental air masses with a high aerosol load. No clear indication of ion-induced nucleation was found considering the behavior of positive small ions during nucleation events.

5 The variation in the concentration of small ions can well be explained by the changes in ion loss due to aerosols (ion sink). Exceptions are the nighttime calms and weak wind, when the increase in the concentration of small ions (up to about $1000 \mathrm{~cm}^{-3}$ ) is probably due to the effect of radon. The concentration of small ions decreases independently of fine aerosol particles (3-500 $\mathrm{nm}$ ) at high humidity (above $98 \%$ ), presumably due to scavenging by fog droplets. The nonlinear correlation between the small ion concentration and the ion sink for the selected hours (wind speed $>0.6 \mathrm{~m} \mathrm{~s}^{-1}$, relative humidity<97\%) was $87 \%$.

The loss of small ions by small ion recombination cannot be ignored, its contribution to the total ion loss was about $16 \%$ in average; the maximum of $75 \%$ was recorded in 15 the case of Arctic clean air advection from the North Atlantic.

The ion sink on aerosols varied in the range of 3.9.10 -4 -5.8.10 $0^{-2} \mathrm{~s}^{-1}$ (commonly $10^{-3}-1.2 \cdot 10^{-3} \mathrm{~s}^{-1}$ ) at the Hyytiälä station. It was mainly determined by the concentration of particles in the size range of $3-500 \mathrm{~nm}$, the contribution of larger particles of the sizes of $0.52-15 \mu \mathrm{m}$ was about $1.5 \%$ in average, and always less than $8 \%$. The 20 main contribution was made by the particles in the Aitken and accumulation mode size ranges. The nucleation mode particles $(3-20 \mathrm{~nm})$ had an effect on the concentration of small ions only sometimes during an intensive generation of nanometer particles followed by a rapid growth of particles towards large sizes.

In the nucleation event days, the minimum in the ion sink occurred before the onset 25 of the generation of nanometer particles or at about the burst peak. Before the onset, the fine aerosols $(3-500 \mathrm{~nm}$ ) were responsible for $37-88 \%$ (commonly $65-83 \%$ ) of the total ion loss due to small ion recombination and attachment to the aerosol particles. The mean ion sink on aerosols was about 1.8 times smaller during the nucleation event days compared to the non-event days, and the mean concentration of small ions was

\section{Air ions in boreal forest air}

U. Hõrrak et al.

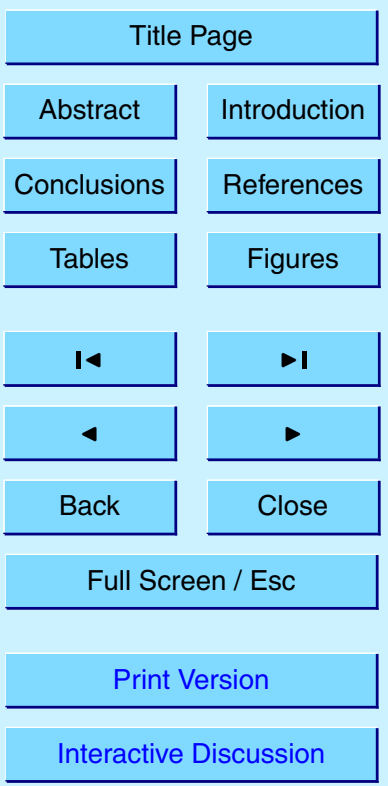

EGU 
correspondingly higher: $530 \mathrm{~cm}^{-3}$ versus $424 \mathrm{~cm}^{-3}$, respectively.

The ion sink is affected by the total concentration of particles and by the changes in the effective attachment coefficient of small ions onto aerosol particles. The effective attachment coefficient (which is nearly proportional to the mean diameter of 5 aerosol particles) varied in the range of $2 \cdot 10^{-7}-3.9 \cdot 10^{-6} \mathrm{~cm}^{3} \mathrm{~s}^{-1}$. It showed a considerable diurnal variation during the nucleation burst days due to transformations in the aerosol particle size distribution initiated by the mixing of boundary layer and new particle formation. During the peak time of nanometer particle generation around noon, the effective attachment coefficient was almost always less than $6 \cdot 10^{-7} \mathrm{~cm}^{3} \mathrm{~s}^{-1}$.

10 The average ionization rate of about 2.8 ion pairs $\mathrm{cm}^{-3} \mathrm{~s}^{-1}$, calculated from the small ion balance equation applying experimental data of aerosol particle size distribution and small ion concentration measurements, is too small for continental stations. The relationship between the concentration of small ions and the ion sink on aerosol particles is far from the dependence predicted by the balance equation of small ions. 15 The best fit to experimental data was found assuming an extra ion loss of $5.2 \cdot 10^{-3} \mathrm{~s}^{-1}$ (presumably due to small ion deposition on the coniferous forest) in addition to the ion sink and additional ionization rate of 2 ion pairs $\mathrm{cm}^{-3} \mathrm{~s}^{-1}$. Therefore, the estimated average total ionization rate at the Hyytiälä station at a height of about $2 \mathrm{~m}$ above the ground during early spring, when the ground was wet and partly covered with snow, 20 was found to be 4.8 ion pairs $\mathrm{cm}^{-3} \mathrm{~s}^{-1}$.

The analysis of the correlation between the concentrations of nanometer aerosol particles and their charged fraction (positive air ions) showed a good qualitative consistency. Considering different nucleation event days when the concentration of charged nanometer particles $(2.5-8 \mathrm{~nm})$ exceeded $120 \mathrm{~cm}^{-3}$, the linear correlation coefficients
ACPD

$5,2749-2790,2005$

Air ions in boreal forest air

U. Hõrrak et al.

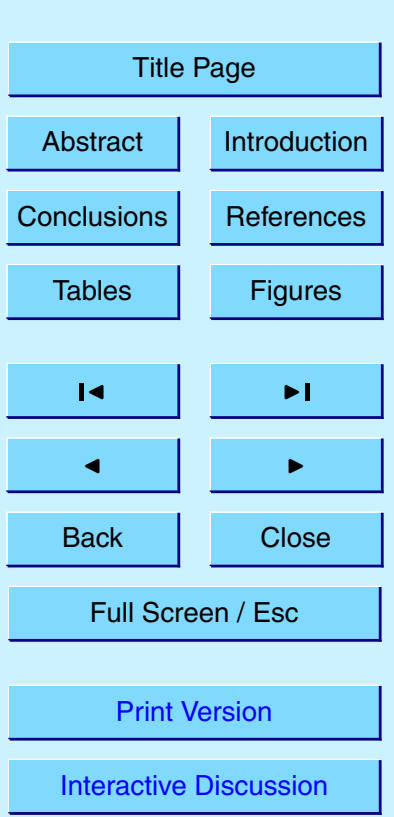

EGU 
for the mean size of the fraction of $5.3 \mathrm{~nm}$. Considering the measuring uncertainties, we cannot state that the excess of the charged nanometer particles of positive polarity is an indication of the overcharge of atmospheric aerosols due to an ion-induced nucleation process. Further study is necessary to specify the nucleation mechanism.

5 Acknowledgements. This research has in part been supported by the Nessling Foundation, the Nordic Center of Excellence (BACCl) and the Estonian Science Foundation through grants 4622 and 6223.

\section{References}

Aalto, P., Hämeri, K., Becker, E., Weber, R., Salm, J., Mäkelä, J. M., Hoell, C., O’Dowd, C. D., Karlsson, H., Hansson, H.-C., Väkevä, M., Koponen, I., Buzorius, G., and Kulmala, M.: Physical characterization of aerosol particles during nucleation events, Tellus, 53B, 344-258, 2001.

Birmili, W., Berresheim, H., Plass-Dülmer, C., Elste, T., Gilge, S., Wiedensohler, A., and Uhrner, U.: The Hohenpeissenberg aerosol formation experiment (HAFEX): A long-term study including size-resolved aerosol, $\mathrm{H}_{2} \mathrm{SO}_{4}, \mathrm{OH}$, and monoterpenes measurements, Atmos. Chem. Phys., 3, 361-376, 2003, SRef-ID: 1680-7324/acp/2003-3-361.

Chalmers, J. A.: Atmospheric Electricity, Pergamon Press, Oxford, London, 1967.

Dolezalek, H.: The atmospheric electric fog effect, Rev. Geophys., 1(2), 231-282, 1963.

Froyd, K. D. and Lovejoy, E. R.: Experimental thermodynamics of cluster ions composed of $\mathrm{H}_{2} \mathrm{SO}_{4}$ and $\mathrm{H}_{2} \mathrm{O}$. 1. Positive ions, J. Phys. Chem. A, 107, 9800-9811, 2003a.

Froyd, K. D. and Lovejoy, E. R.: Experimental thermodynamics of cluster ions composed of $\mathrm{H}_{2} \mathrm{SO}_{4}$ and $\mathrm{H}_{2} \mathrm{O}$. 2. Measurements and a initio structures of negative ions, J. Phys. Chem. A, 107, 9812-9824, 2003b.

Fuchs, N. A. and Sutugin, A. G.: High-dispersed aerosols, in: Topics in Current Aerosol Research, edited by: Hidy, G. M. and Brock, J. R., Pergamon, Oxford, 2, 1-60, 1971.

Hanson, D. R. and Eisele, F. L.: Measurement of prenucleation molecular clusters in the $\mathrm{NH}_{3}$, $\mathrm{H}_{2} \mathrm{SO}_{4}, \mathrm{H}_{2} \mathrm{O}$ system, J. Geophys. Res., 107(D12), doi:10.1029/2001JD001100, 2002.

Air ions in boreal forest air

U. Hõrrak et al.

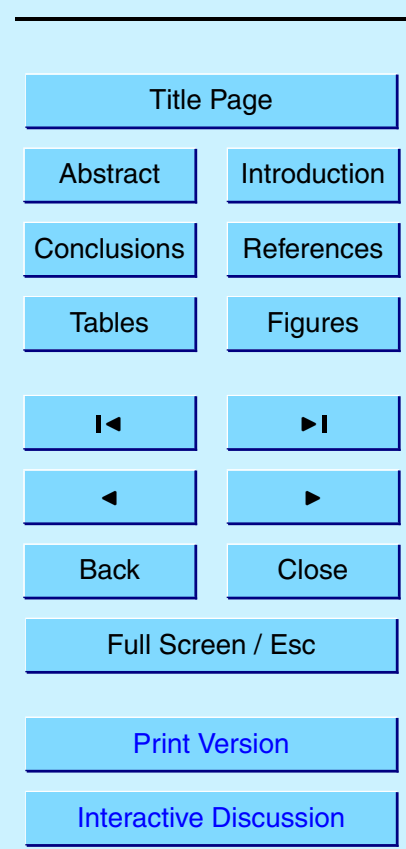


Hatakka, J., Paatero, J., Viisanen, Y., and Mattsson, R.: Variations of external radiation due to meteorological and hydrological factors in central Finland, Radiochemistry, MAIK Nauka/Interperiodica Publishing, 40(6), 515-519, 1998.

Hoppel, W. A.: Ion-aerosol attachment coefficients, ion depletion, and the charge distribution on aerosols, J. Geophys. Res., 90, 5917-5923, 1985.

Hoppel, W. A. and Frick, G. M.: Ion-aerosol attachment coefficients and the steady-state charge distribution on aerosols in a bipolar ion environment, Aerosol Sci. Technol., 5, 1-21, 1986.

Hoppel, W. A., Frick, G. M., Fitzgerald, J. W., and Larson, R. E.: Marine boundary layer measurements of new particle formation and the effects nonprecipitating clouds have on aerosol 10 size distribution, J. Geophys. Res., 99, 14 443-14 459, 1994.

Hoppel, W. A. and Frick, G. M.: The nonequilibrium character of the aerosol charge distributions produced by neutralizers, Aerosol Sci. Technol., 12, 471-496, 1990.

Hoppel, W. A., Anderson, R. V., and Willett, J. C.: Atmospheric electricity in the planetary boundary layer, In: The Earth's Electrical Environment, National Academy Press, Washington, D.C., 149-165, 1986.

Hõrrak, U., Aalto, P., Salm, J., and Kulmala, M.: Characterization of air ions during nucleation events in boreal forest air, Report Series in Aerosol Science (Helsinki), 59, 196-201, 2003a.

Hõrrak, U., Salm, J., and Tammet, H.: Diurnal variation in the concentration of air ions of different mobility classes at a rural area, J. Geophys. Res., 108(D20), 4653, doi:10.1029/2002JD003240, 2003b.

Hõrrak, U., Salm, J., and Tammet, H.: Statistical characterization of air ion mobility spectra at Tahkuse Observatory: Classification of air ions, J. Geophys. Res., 105, 9291-9302, 2000.

Hõrrak, U., Salm, J., and Tammet, H.: Bursts of intermediate ions in atmospheric air, J. Geophys. Res., 103, 13909-13915, 1998a.

Hõrrak, U., Mirme, A., Salm, J., Tamm, E., and Tammet, H.: Air ion measurements as a source of information about atmospheric aerosols, Atmos. Res., 46, 233-242, 1998b.

Hämeri, K., Väkevä, M., Aalto, P. P., Kulmala, M., Swietlicki, E., Zhou, J., Seidl, W., Becker, E., and O'Dowd, C. D.: Hygroscopic and CCN properties of aerosol particles in boreal forests, Tellus, 53B, 359-379, 2001.

30 Israël, H.: Atmospheric Electricity, Vol. I, Israel Program for Scientific Translations, Jerusalem, 1970.

Israël, H.: Atmospheric Electricity, Vol. II, Israel Program for Scientific Translations, Jerusalem, 1973.

ACPD

5, 2749-2790, 2005

Air ions in boreal forest air

U. Hõrrak et al.

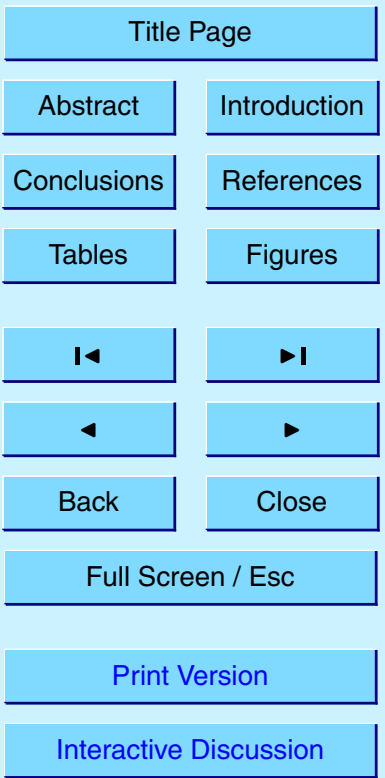

EGU 
Kim, T. O., Ishida, T., Adachi, M., Okuyama, K., and Seinfeld, J. H.: Nanometer-sized particle formation from $\mathrm{NH}_{3} / \mathrm{SO}_{2} / \mathrm{H}_{2} \mathrm{O}$ /air mixtures by ionizing irradiation, Aerosol Sci. Technol., 29, 111-125, 1998.

Kim, T. O., Adachi, M., Okuyama, K., and Seinfeld, J. H.: Experimental measurement of com5 petitive ion-induced and binary homogeneous nucleation in $\mathrm{SO}_{2} / \mathrm{H}_{2} \mathrm{O} / \mathrm{N}_{2}$ mixtures, Aerosol Sci. Technol., 26, 527-543, 1997.

Korhonen, P., Kulmala, M., Laaksonen, A., Viisanen, Y., McGraw, R., and Seinfeld, J.: Ternary nucleation of $\mathrm{H}_{2} \mathrm{SO}_{4}, \mathrm{NH}_{3}$ and $\mathrm{H}_{2} \mathrm{O}$ in the atmosphere, J. Geophys. Res., 104, 26349$26353,1999$.

10 Kulmala, M., Vehkamäki, H., Petäjä, T., Dal Maso, M., Lauri, A., Kerminen, V.-M., Birmili, W., and McMurry, P. H.: Formation and growth rates of ultrafine atmospheric particles: a review of observations, J. Aerosol Sci., 35, 143-176, 2004a.

Kulmala, M., Laakso, L., Lehtinen, K. E. J., Riipinen, I., Dal Maso, M., Anttila, T., Kerminen, V.-M., Hõrrak, U., Vana, M., and Tammet, H.: Initial steps of aerosol growth, Atmos. Chem. Phys., 4, 2553-2560, 2004b, SRef-ID: 1680-7324/acp/2004-4-2553.

Kulmala, M., Hämeri, K., Aalto, P. P., Mäkelä, J. M., Pirjola, L., Nilsson, E. D., Buzorius, G., Rannik,Ü., Dal Maso, M., Seidl, W., Hoffman, T., Janson, R., Hansson, H.-C., Viisanen, Y., Laaksonen, A., and O'Dowd, C. D.: Overview of the international project on biogenic aerosol 20 formation in the boreal forest (BIOFOR), Tellus, 53B, 324-343, 2001a.

Kulmala, M., Dal Maso, M., Mäkelä, J. M., Pirjola, L., Väkevä, M., Aalto, P. P, Miikkulainen, P., Hämeri, K., and O'Dowd, C. D.: On the formation, growth and composition of nucleation mode particles, Tellus, 53B, 479-490, 2001b.

Kulmala, M., Pirjola, L., and Mäkelä, J. M.: Stable sulphate clusters as a source of new atmospheric particles, Nature, 404, 66-69, 2000.

Laakso, L., Petäjä, T., Lehtinen, K. E. J., Kulmala, M., Paatero, J., Hõrrak, U., Tammet, H., and Joutsensaari, J.: Ion production rate in a boreal forest based on ion, particle and radiation measurements, Atmos. Chem. Phys., 4, 1933-1943, 2004a,

SRef-ID: 1680-7324/acp/2004-4-1933.

so Laakso, L., Anttila, T., Lehtinen, K. E. J., Aalto, P. P., Kulmala, M., Hõrrak, U., Paatero, J., Hanke, M., and Arnold, F.: Kinetic nucleation and ions in boreal forest particle formation events, Atmos. Chem. Phys., 4, 2353-2366, 2004b,

Air ions in boreal forest air

U. Hõrrak et al. SRef-ID: 1680-7324/acp/2004-4-2353. 
Laakso, L., Mäkelä, J. M., Pirjola, L., and Kulmala, M.: Model studies on ion-induced nucleation in the atmosphere, J. Geophys. Res., 107(D20), 4427, doi:10.1029/2002JD002140, 2002.

Mäkelä, J. M., Salm, J., Smirnov, V. V., Koponen, I., Paatero, J., and Pronin, A. A.: Measurements of the mobility distribution of air ions as a source of information for the study of

5 aerosol generation, in: Proceedings of 12th International Conference on Atmospheric Electricity, 2003, Versailles, 793-796, 2003.

Mäkelä, J. M., Salm, J., Smirnov, V. V., Koponen, I., Paatero, J., and Pronin A. A.: Electrical charging state of fine and ultrafine particles in boreal forest air, J. Aerosol Sci., 32, S149S150, 2001a.

10 Mäkelä, J. M., Yli-Koivisto, S., Hiltunen, V., Seidl, W., Swietlicki, E., Teinilä, K., Sillanpää, M., Koponen, I. K., Paatero, J., Rosman, K., and Hämeri, K.: Chemical composition of aerosol during particle formation events in Boreal forest, Tellus, 53B, 380-393, 2001b.

Mäkelä, J. M., Dal Maso, M., Pirjola, L., Keronen, P., Laakso, L., Kulmala, M., and Laaksonen, A.: Characteristics of the aerosol particle formation events observed at a boreal forest site in southern Finland, Boreal Environment Research, 4, 299-313, 2000.

Napari, I., Kulmala, M., and Vehkamäki, H.: Ternary nucleation of inorganic acids, ammonia, and water, J. Chem. Phys., 117, 8418-8425, 2002.

Nilsson, E. D., Paatero, J., and Boy, M.: Effects of air masses and synoptic weather on aerosol formation in the continental boundary layer, Tellus, 53B, 462-478, 2001a.

20 Nilsson, E. D., Rannik, Ü., Buzorius, G., O’Dowd, C., Boy, M., Paatero J., and Laakso, L.: Effects of the continental boundary layer evolution, convection, turbulence and entrainment on aerosol formation, Tellus, 53B, 441-461, 2001b.

Penttinen, L., Paatero, J., Viisanen, Y., and Kulmala, M.: Seasonal and diurnal variation of airbone radon-222 at Hyytiälä, Finland, Report Series in Aerosol Science (Helsinki), 59, 79$2582,2003$.

Porstendörfer, J.: Properties and behaviour of radon and thoron and their decay products in the air, J. Aerosol Sci., 25, 219-263, 1994.

Raes, F. and Janssens, A.: Ion-induced aerosol formation in a $\mathrm{H}_{2} \mathrm{O}-\mathrm{H}_{2} \mathrm{SO}_{4}$ system. I. Extension of the classical theory and search for experimental evidence, J. Aerosol Sci., 16, 217-227, 301985.

Raes, F. and Van Dingenen, R.: Simulation of condensation and cloud condensation nuclei from biogenic $\mathrm{SO}_{2}$ in the remote marine boundary layer, J. Geophys. Res., 97, 12901$12912,1992$.

ACPD

$5,2749-2790,2005$

\section{Air ions in boreal forest air}

U. Hõrrak et al.

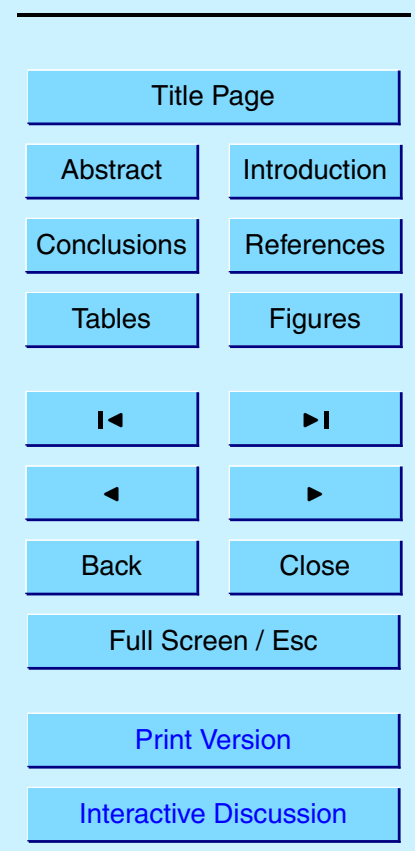

EGU 
Ramamurthi, M., Strydom, R., Hopke, P. K., and Holub, R. F.: Nanometer and ultrafine aerosols from radon radiolysis, J. Aerosol Sci., 24, 393-407, 1993.

Reischl, G. P., Mäkelä, J. M., Karch, R., and Necid, J.: Bipolar charging of ultrafine particles in the size range below $10 \mathrm{~nm}$, J. Aerosol Sci., 27, 931-949, 1996.

5 Tamm, E., Hõrrak, U., Mirme, A., and Vana, M.: On the charge distribution on atmospheric nanoparticles, J. Aerosol Sci., 32, S347-S348, 2001.

Tammet, H., Kimmel, V., and Israelsson, S.: Effect of atmospheric electricity on dry deposition of airborne particles from atmosphere, Atmos. Environ., 35, 3413-3419, 2001.

Tammet, H. and Kimmel, V.: Electrostatic deposition of radon daughter clusters on the trees, J.

$10 \quad$ Aerosol Sci., 29, S473-S474, 1998.

Tammet, H.: Aerosol electrical density: Interpretation and principles of measurement, Report Series in Aerosol Science (Helsinki), 19, 128-133, 1991.

Tammet, $\mathrm{H} .:$ The aspiration method for the determination of atmospheric ion-spectra, Israel Program for Scientific Translations, Jerusalem, 1970.

Tunved, P., Hansson, H.-C., Kulmala, M., Aalto, P., Viisanen, Y., Karlsson, H., Kristensson, A., Swietlicki, E., Dal Maso, M., Strom, J., and Komppula, M.: One year boundary layer aerosol size distribution data from five nordic background stations, Atmos. Chem. Phys., 3, 21832205, 2003,

SRef-ID: 1680-7324/acp/2003-3-2183.

20 Wilhelm, S., Eichkorn, S., Wiedner, D., Pirjola, L., and Arnold, F.: Ion-induced aerosol formation: new insights from laboratory measurements of mixed cluster ions $\mathrm{HSO}_{4}^{-}\left(\mathrm{H}_{2} \mathrm{SO}_{4}\right)_{a}\left(\mathrm{H}_{2} \mathrm{O}\right)_{w}$ and $\mathrm{H}^{+}\left(\mathrm{H}_{2} \mathrm{SO}_{4}\right)_{a}\left(\mathrm{H}_{2} \mathrm{O}\right)_{w}$, Atmos. Environ., 38, 1735-1744, 2004.

Yu F. and Turco, R. P.: Ultrafine aerosol formation via ion-mediated nucleation, Geophys. Res. Lett., 27, 883-886, 2000.

$25 \mathrm{Yu}, \mathrm{F}$. and Turco, R. P.: From molecular clusters to nanoparticles: Role of ambient ionization in tropospheric aerosol formation, J. Geophys. Res., 106, 4797-4814, 2001.

ACPD

$5,2749-2790,2005$

Air ions in boreal forest air

U. Hõrrak et al.

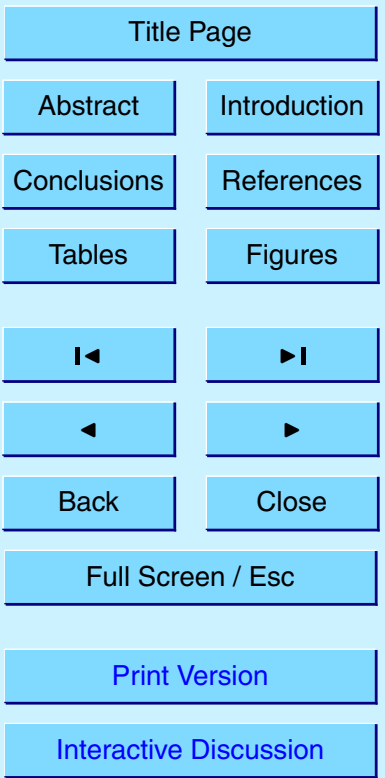

EGU 


\section{ACPD}

Table 1. Descriptive statistics of the positive small ion concentration $(n)$, effective attachment coefficient $\left(\beta_{\text {eff }}\right)$, the sink of small ions on aerosol particles of 3-500 $\mathrm{nm}\left(S_{a}\right)$, ion loss due to the recombination of small ions $(\alpha \cdot n)$, the ionisation rate $(q)$, the total concentration of aerosol particles $\left(N_{t o t}\right)$ and the ratio of ion loss due to the recombination to total ion loss (last row). 31 March-29 April 1999, Hyytiälä.

a) Nucleation event days (number of measurements 1813).

\begin{tabular}{|c|c|c|c|c|c|c|c|c|c|}
\hline & Mean & Median & Min & Max & $\begin{array}{l}\text { Lower } \\
\text { Quartile }\end{array}$ & $\begin{array}{c}\text { Upper } \\
\text { Quartile }\end{array}$ & $\begin{array}{c}\text { Percentile } \\
10\end{array}$ & $\begin{array}{c}\text { Percentile } \\
90\end{array}$ & $\begin{array}{l}\text { Std. } \\
\text { Dev. }\end{array}$ \\
\hline$n, \mathrm{~cm}^{-3}$ & 530 & 513 & 110 & 1183 & 430 & 613 & 364 & 731 & 145 \\
\hline$\beta_{e f f}, 10^{-6} \mathrm{~cm}^{3} \mathrm{~s}^{-1}$ & 1.27 & 1.17 & 0.20 & 3.30 & 0.63 & 1.83 & 0.41 & 2.35 & 0.73 \\
\hline$S_{a}, 10^{-3} \mathrm{~s}^{-1}$ & 4.15 & 3.92 & 0.39 & 11.90 & 2.72 & 5.42 & 1.67 & 6.70 & 1.98 \\
\hline$\alpha \cdot n, 10^{-3} \mathrm{~s}^{-1}$ & 0.795 & 0.769 & 0.165 & 1.775 & 0.645 & 0.92 & 0.545 & 1.096 & 0.218 \\
\hline$q, \mathrm{~cm}^{-3} \mathrm{~s}^{-1}$ & 2.49 & 2.30 & 0.77 & 7.57 & 1.84 & 2.93 & 1.47 & 3.74 & 0.94 \\
\hline$N_{t o t}$ & 4072 & 3474 & 588 & 18980 & 2278 & 5343 & 1422 & 7358 & 2579 \\
\hline$\alpha \cdot n /\left(\alpha \cdot n+S_{a}\right)$ & 0.199 & 0.164 & 0.024 & 0.746 & 0.113 & 0.263 & 0.076 & 0.352 & 0.126 \\
\hline
\end{tabular}

b) Non-event days (number of measurements 1754).

\begin{tabular}{lccccccccc}
\hline & Mean & Median & Min & $\begin{array}{c}\text { Max } \\
\text { Quartile }\end{array}$ & $\begin{array}{c}\text { Lower } \\
\text { Quartile }\end{array}$ & $\begin{array}{c}\text { Upper } \\
10\end{array}$ & $\begin{array}{c}\text { Percentile } \\
90\end{array}$ & $\begin{array}{c}\text { Percentile } \\
\text { Dev. }\end{array}$ & Std. \\
\hline$n, \mathrm{~cm}^{-3}$ & 424 & 410 & 120 & 1175 & 282 & 539 & 219 & 659 & 180 \\
$\beta_{\text {eff }}, 10^{-6} \mathrm{~cm}^{3} \mathrm{~s}^{-1}$ & 2.23 & 2.24 & 0.63 & 3.85 & 1.64 & 2.85 & 1.13 & 3.17 & 0.74 \\
$S_{a}, 10^{-3} \mathrm{~s}^{-1}$ & 7.59 & 5.37 & 1.18 & 58.70 & 4.05 & 8.36 & 3.41 & 16.00 & 6.39 \\
$\alpha \cdot n, 10^{-3} \mathrm{~s}^{-1}$ & 0.636 & 0.614 & 0.181 & 1.762 & 0.422 & 0.809 & 0.328 & 0.989 & 0.27 \\
$q, \mathrm{~cm}^{-3} \mathrm{~s}^{-1}$ & 3.03 & 2.77 & 0.55 & 14.56 & 1.89 & 3.77 & 1.39 & 4.89 & 1.59 \\
$N_{t o t}$ & 3518 & 2910 & 536 & 25449 & 2050 & 4338 & 1388 & 5827 & 2623 \\
$\alpha \cdot n /\left(\alpha \cdot n+S_{a}\right)$ & 0.110 & 0.104 & 0.005 & 0.483 & 0.050 & 0.152 & 0.022 & 0.201 & 0.073 \\
\hline
\end{tabular}

$5,2749-2790,2005$

Air ions in boreal forest air

U. Hõrrak et al.

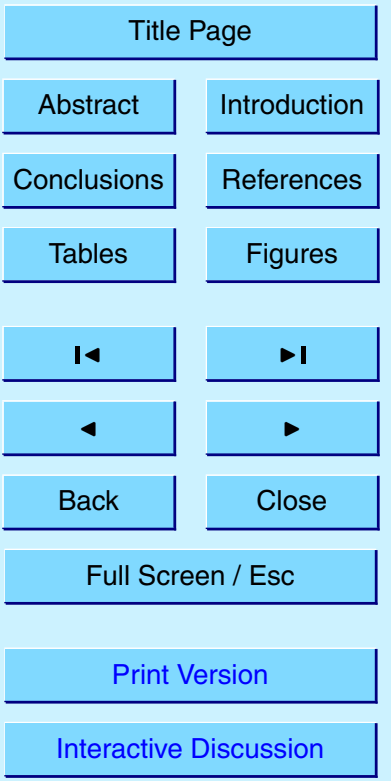

EGU 


\section{ACPD}

$5,2749-2790,2005$

Air ions in boreal forest air

U. Hõrrak et al.

Table 2. Descriptive statistics of the concentration of positive aerosol ions: light intermediate ions $(m)$, heavy intermediate ions $(N)$, and the corresponding classes of nanometer aerosol particles $(A)$ of the sizes of $2.5-8 \mathrm{~nm}$ and $8-20 \mathrm{~nm}$ during the nucleation event days/ non-event days. The number of measurements during the nucleation event days is 1506 and on the non-event days 1503. 31 March-29 April 1999, Hyytiälä.

\begin{tabular}{lccccccccc}
\hline & Mean & Median & Min & Max & $\begin{array}{c}\text { Lower } \\
\text { Quartile }\end{array}$ & $\begin{array}{c}\text { Upper } \\
\text { Quartile }\end{array}$ & $\begin{array}{c}\text { Percentile } \\
10\end{array}$ & $\begin{array}{c}\text { Percentile } \\
90\end{array}$ & $\begin{array}{c}\text { Std. } \\
\text { Dev. }\end{array}$ \\
\hline$m, \mathrm{~cm}^{-3}$ & $67 / 36$ & $57 / 33$ & $0 / 0$ & $428 / 130$ & $38 / 21$ & $81 / 48$ & $27 / 11$ & $125 / 63$ & $45 / 21$ \\
$N, \mathrm{~cm}^{-3}$ & $96 / 50$ & $77 / 47$ & $0 / 0$ & $414 / 295$ & $41 / 26$ & $140 / 66$ & $17 / 13$ & $196 / 89$ & $72 / 35$ \\
$A_{2.5-8}, \mathrm{~cm}^{-3}$ & $579 / 78$ & $123 / 19$ & $0 / 0$ & $12030 / 2290$ & $22 / 4$ & $671 / 66$ & $4 / 0.2$ & $1777 / 217$ & $1067 / 164$ \\
$A_{8-20}, \mathrm{~cm}^{-3}$ & $1462 / 371$ & $667 / 186$ & $23 / 6$ & $11040 / 7477$ & $283 / 73$ & $2186 / 389$ & $144 / 38$ & $3941 / 769$ & $1667 / 657$ \\
\hline
\end{tabular}

* Negative values are corrected to be equal to zero.

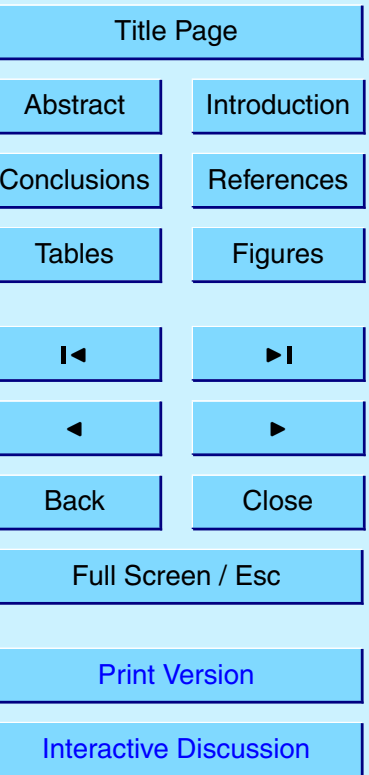

EGU 


\section{ACPD}

Table 3. The classification of nucleation events and the growth rates of newly formed particles during the BIOFOR III campaign (Kulmala et al., 2001a), positively charged fractions of aerosol particles, the correlation coefficients between the concentrations of positive air ions and aerosol particles in coinciding size ranges, and the maximum concentrations of aerosol particles during various nucleation event days. 2-29 April 1999, Hyytiälä.

\begin{tabular}{lcccccccc}
\hline \multirow{2}{*}{ Date } & Class & \begin{tabular}{c} 
Growth \\
rate \\
\cline { 4 - 8 }
\end{tabular} & & \multicolumn{3}{c}{ Size class of particles 2.5-8 $\mathrm{nm}$} & \multicolumn{3}{c}{ Size class of particles 8-20 $\mathrm{nm}$} \\
\cline { 4 - 8 } & & $\begin{array}{c}\text { Charged } \\
\text { fraction } \\
(\%)\end{array}$ & $\begin{array}{c}\text { Correlation } \\
\text { coefficient } \\
(\%)\end{array}$ & $\begin{array}{c}\text { Maximum of } \\
\text { aerosols } \\
\left(\mathrm{cm}^{-3}\right)\end{array}$ & $\begin{array}{c}\text { Charged } \\
\text { fraction } \\
(\%)\end{array}$ & $\begin{array}{c}\text { Correlation } \\
\text { coefficient } \\
(\%)\end{array}$ & $\begin{array}{c}\text { Maximum of } \\
\text { aerosols } \\
\left(\mathrm{cm}^{-3}\right)\end{array}$ \\
\hline 990402 & 1 & 6.7 & 4.9 & 83.6 & 2050 & 3.8 & 98.1 & 6810 \\
990403 & 2 & 2.2 & 3.0 & 43.5 & 840 & 4.2 & 95.4 & 3590 \\
990404 & 1 & 3.5 & 3.2 & 94.5 & 6470 & 3.9 & 94.5 & 9040 \\
990405 & 1 & 6.7 & 3.5 & 98.3 & 12030 & 3.5 & 94.1 & 11040 \\
990406 & 1 & 3.5 & 5.0 & 91.3 & 3290 & 4.0 & 87.7 & 5640 \\
990408 & 2 & 5.4 & 4.7 & 85.5 & 1790 & 4.3 & 95.7 & 4240 \\
990410 & 3 & 2.2 & 6.0 & 89.6 & 3500 & 3.9 & 90.2 & 3650 \\
990412 & 1 & 4.4 & 3.2 & 88.2 & 4390 & 3.7 & 95.6 & 4630 \\
990413 & 2 & 2.2 & 3.8 & 52.4 & 1400 & 3.4 & 92.3 & 5320 \\
990414 & 1 & 5.4 & 4.4 & 94.3 & 3480 & 4.2 & 95.8 & 4780 \\
990419 & 1 & 4.4 & 4.0 & 94.4 & 4450 & 5.1 & 89.8 & 2430 \\
990421 & 3 & 6.7 & $1.2^{*}$ & 4.4 & 270 & $2.0^{*}$ & 35.4 & 1710 \\
990427 & 2 & 4.4 & $0.4^{*}$ & 5.3 & 1080 & $0.4^{*}$ & 2.9 & 800 \\
990429 & 3 & 3.5 & 5.6 & 91.4 & 2770 & 4.4 & 97.5 & 5370 \\
\hline
\end{tabular}

$5,2749-2790,2005$

Air ions in boreal forest air

U. Hõrrak et al.

${ }^{\star}$ Estimates are of low significance.

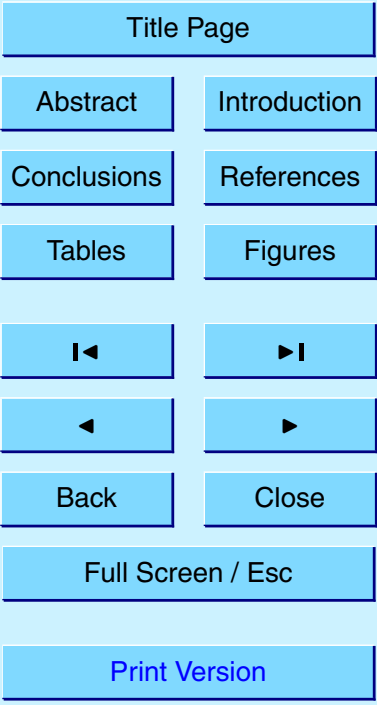

Interactive Discussion

EGU 


\section{ACPD}

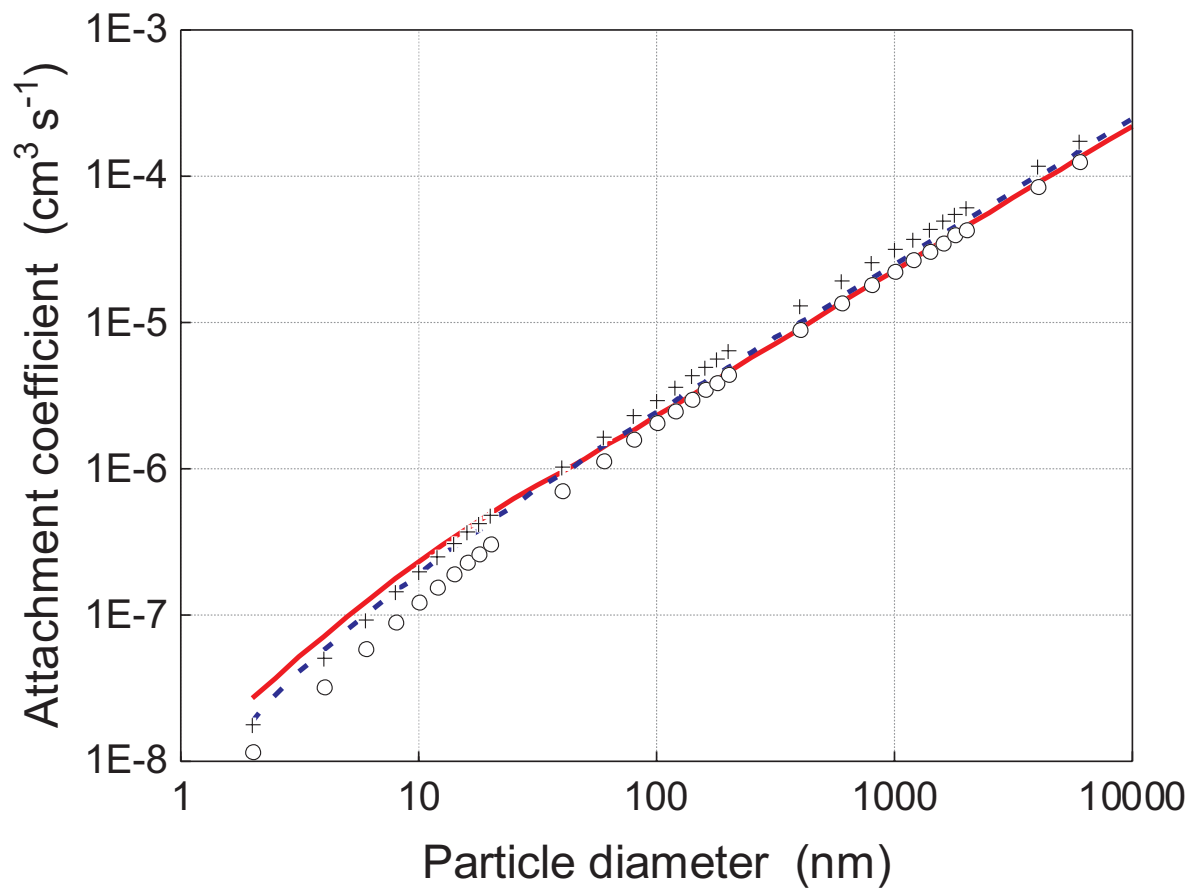

$5,2749-2790,2005$

Air ions in boreal forest air

U. Hõrrak et al.

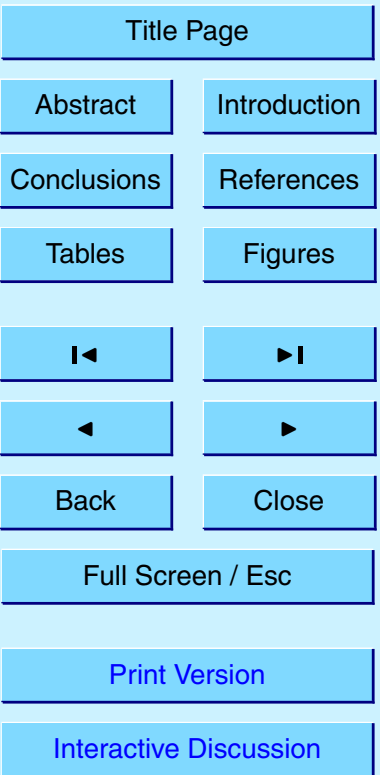

Fig. 1. Equivalent or single size ion-aerosol attachment coefficient as a function of particle size $(2 \mathrm{~nm}-10 \mu \mathrm{m})$. Solid line: model calculations (Eqs. 4-6); dashed line: approximation function (Eq. 7); plus sign (+) and open circles (O): calculations based on Eq. (6) and the tabulated results of attachment coefficients for ions with the mobility of $1.3 \mathrm{~cm}^{2} \mathrm{~V}^{-1} \mathrm{~s}^{-1}$ and the mass of $200 \mathrm{amu}$; and of $1.8 \mathrm{~cm}^{2} \mathrm{~V}^{-1} \mathrm{~s}^{-1}$ and the mass of $100 \mathrm{amu}$, respectively (Hoppel and Frick, 1990). 


\section{ACPD}

5, 2749-2790, 2005

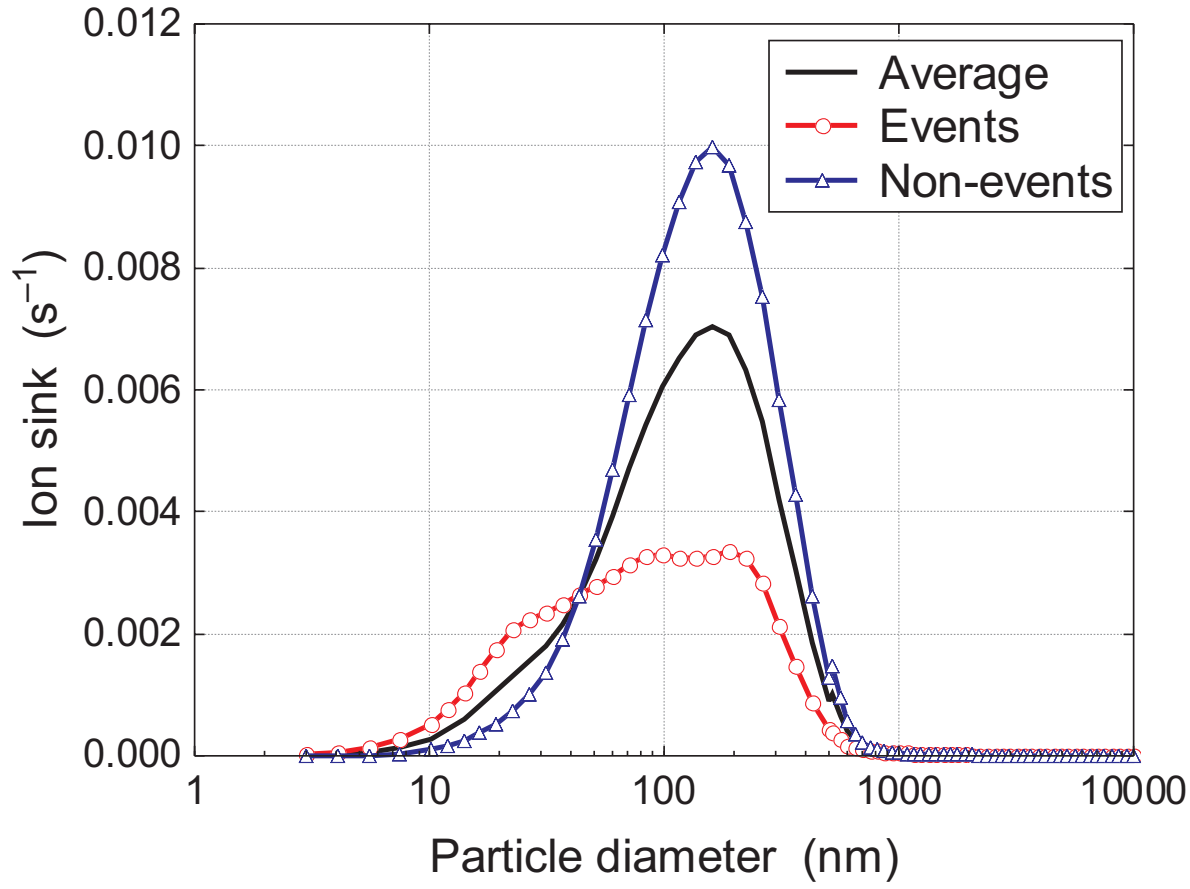

Air ions in boreal forest air

U. Hõrrak et al.

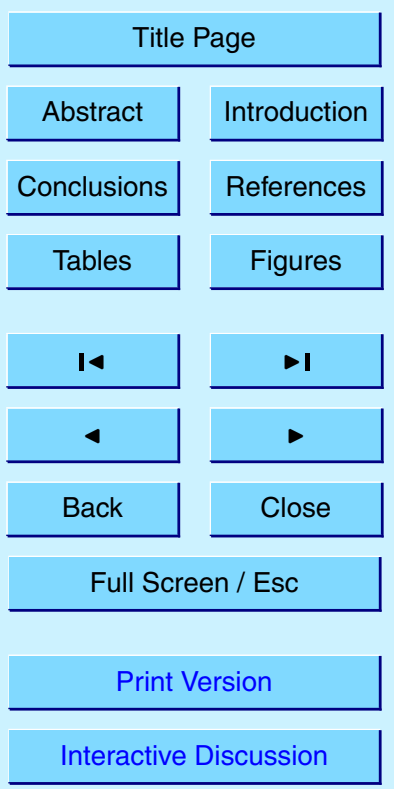

EGU 


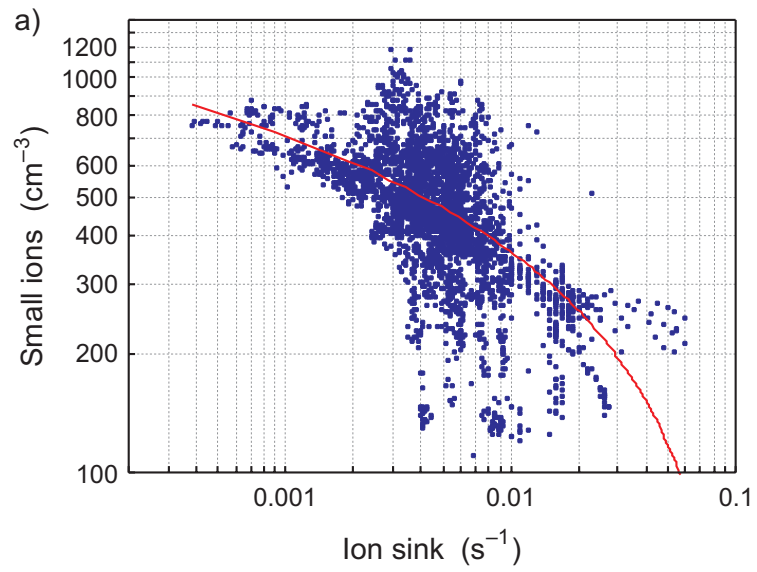

ACPD

$5,2749-2790,2005$

\section{Air ions in boreal forest air}

U. Hõrrak et al.
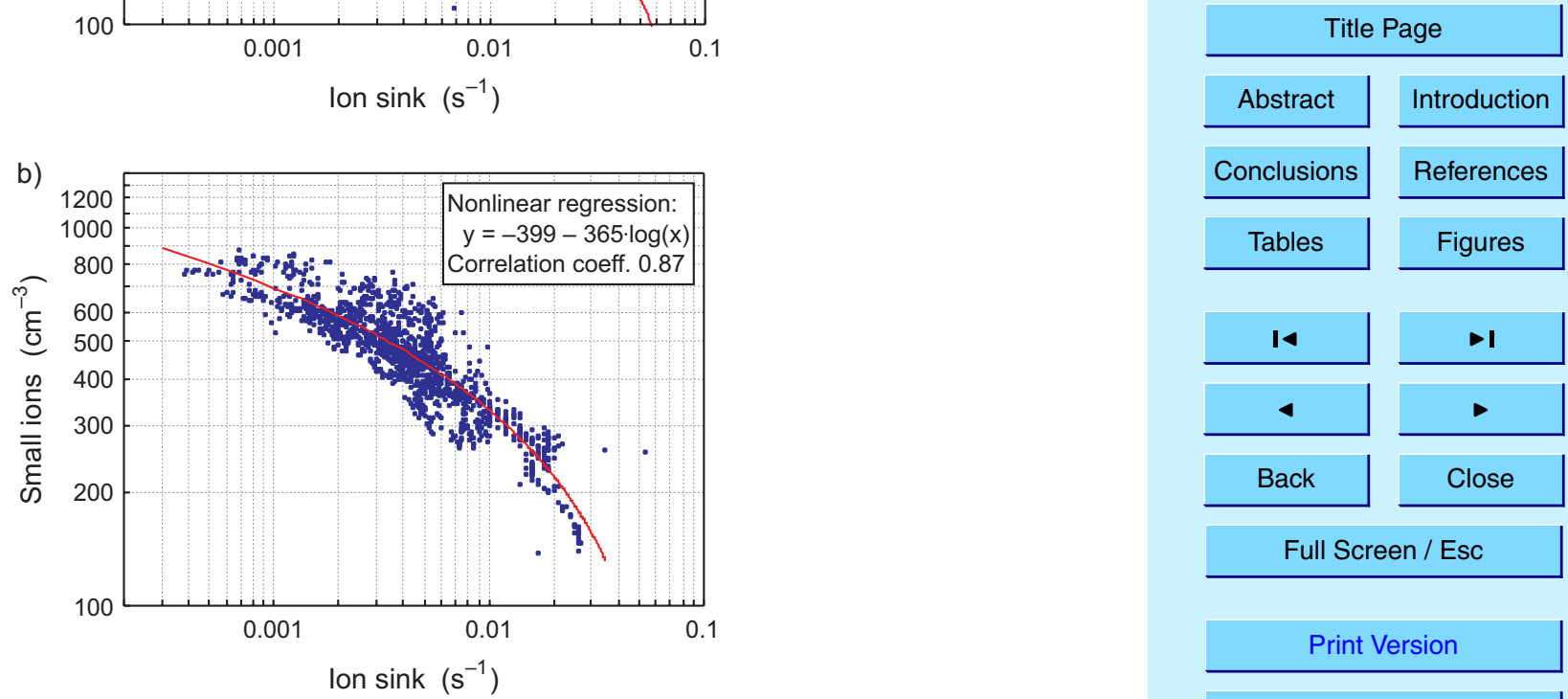

Interactive Discussion

Fig. 3. Scatterplot of the concentration of positive small air ions $(n)$ versus ion sink $\left(S_{a}\right)$ due to aerosol particles $(3-500 \mathrm{~nm})$ and a logarithmic regression line. (a) all the data, (b) selected data when no fog was recorded, relative humidity is less than $97 \%$, and the wind speed is higher than $0.6 \mathrm{~m} \mathrm{~s}^{-1}$. 31 March-29 April 1999, Hyytiälä station. 


\section{ACPD}

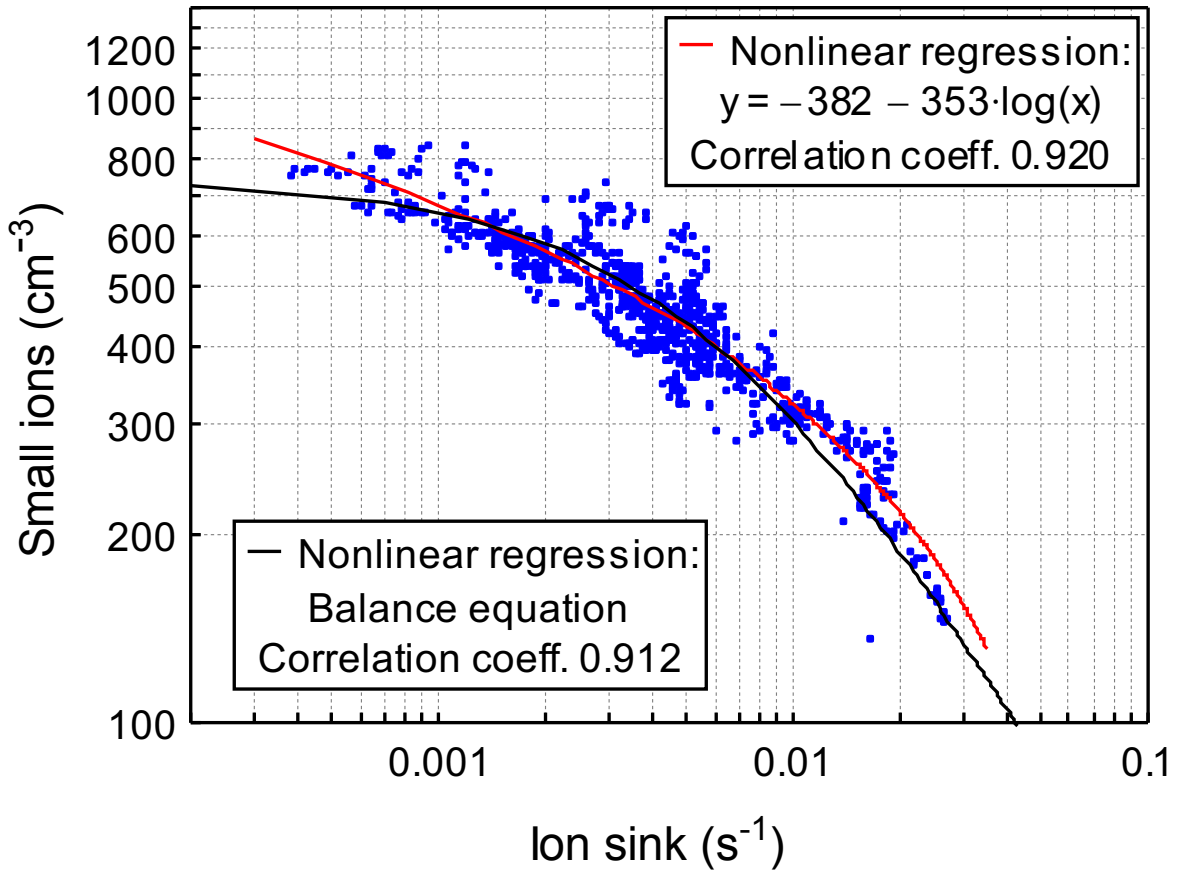

$5,2749-2790,2005$

Air ions in boreal forest air

U. Hõrrak et al.

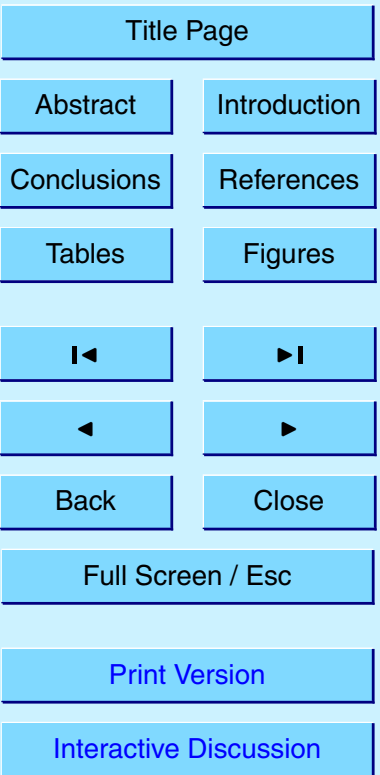

Fig. 4. Scatterplot of the concentration of positive small air ions $(n)$ versus ion sink $\left(S_{a}\right)$ due to aerosol particles $(3-500 \mathrm{~nm})$. Comparison of experimental data and the results derived from the balance equation assuming the ionization rate of 4.8 ion pairs $\mathrm{cm}^{-3} \mathrm{~s}^{-1}$, an extra ion loss of $0.0052 \mathrm{~s}^{-1}$ and the recombination coefficient of $1.5 \cdot 10^{-6} \mathrm{~cm}^{3} \mathrm{~s}^{-1}$. Selected data: relative humidity $<97 \%$, wind speed $>1 \mathrm{~m} \mathrm{~s}^{-1}$. 31 March-29 April 1999, Hyytiälä station. 


\section{ACPD}

$5,2749-2790,2005$

Air ions in boreal forest air
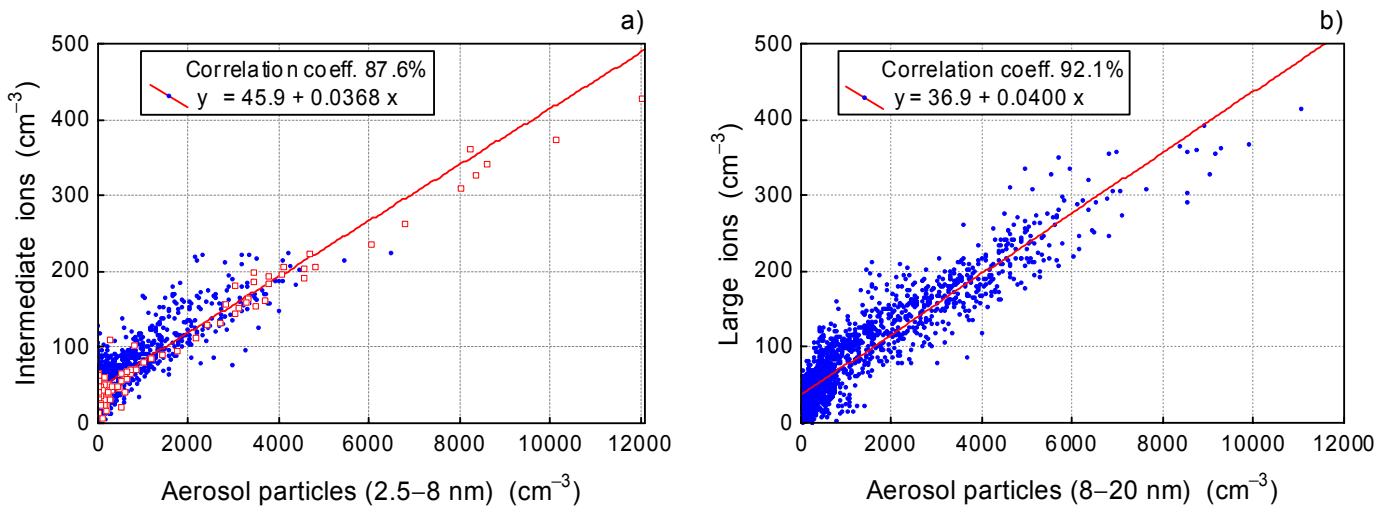

Fig. 5. Scatterplot between the concentrations of positive aerosol ions and aerosol particles: (a) aerosol ions $(m ; 2.5-8 \mathrm{~nm})$, or intermediate ions, versus nanometer aerosol particles (2.5$8 \mathrm{~nm}$ ). The data points corresponding to 5 April are marked with squares ( $\square$ ). (b) Aerosol ions $(N$; 8-ca $20 \mathrm{~nm})$, or large air ions, versus aerosol particles $(8-20 \mathrm{~nm})$. Nucleation event days, 31 March-29 April 1999, Hyytiälä station.

U. Hõrrak et al.

Title Page

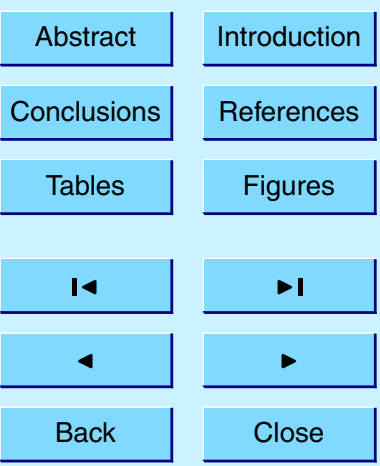

Full Screen / Esc

Print Version

Interactive Discussion 


\section{ACPD}

a)

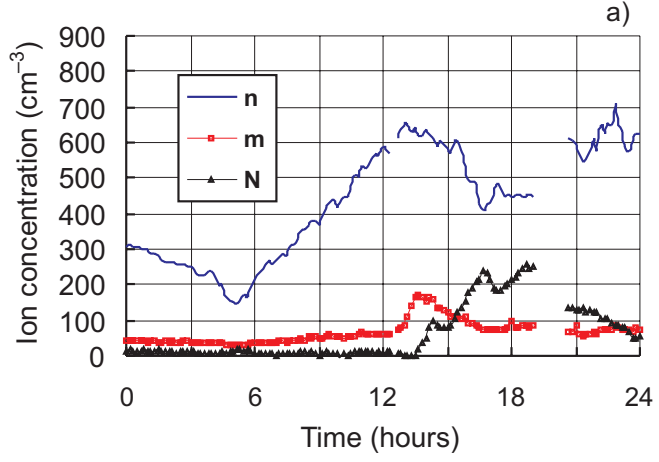

c)

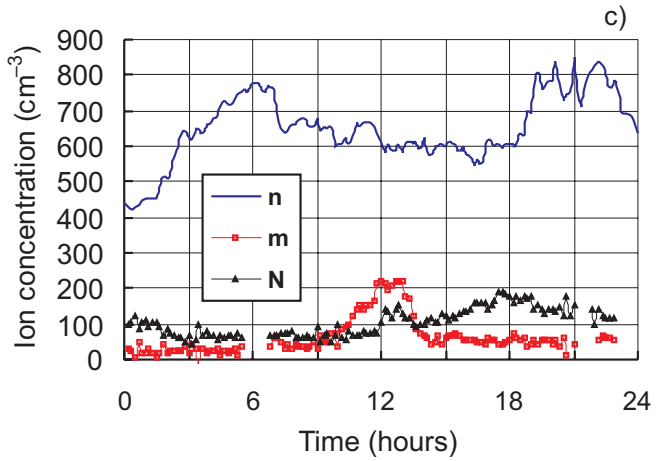

b)

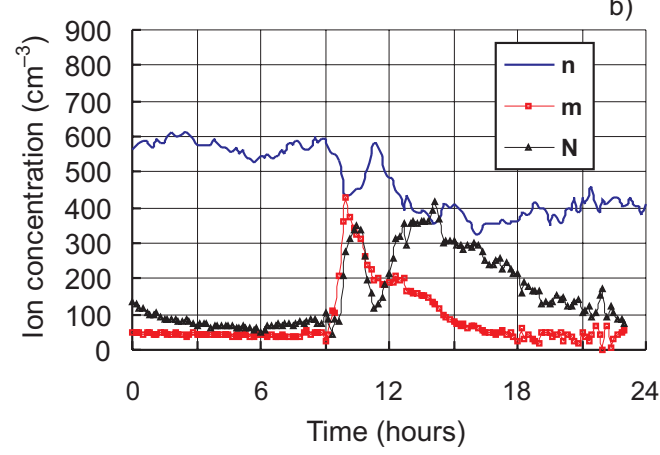

d)

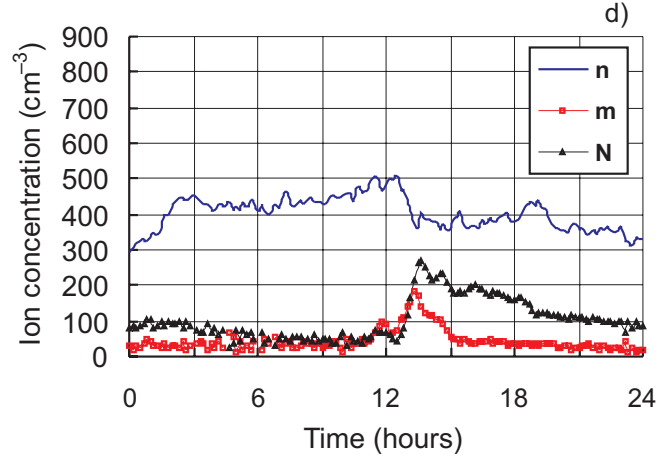

5, 2749-2790, 2005

Air ions in boreal forest air

U. Hõrrak et al.

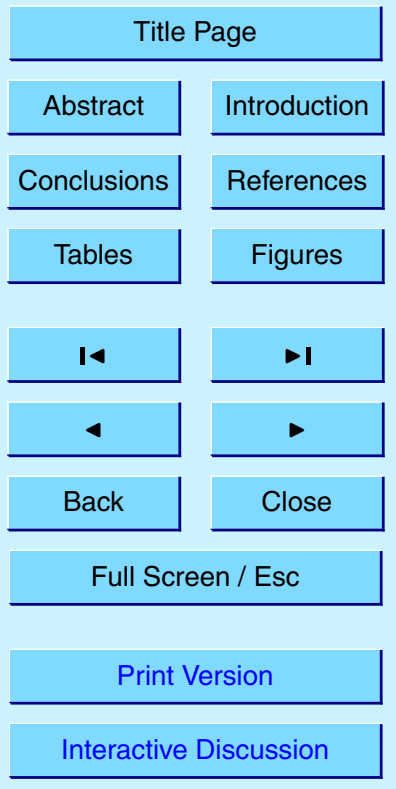

EGU 


\section{ACPD}
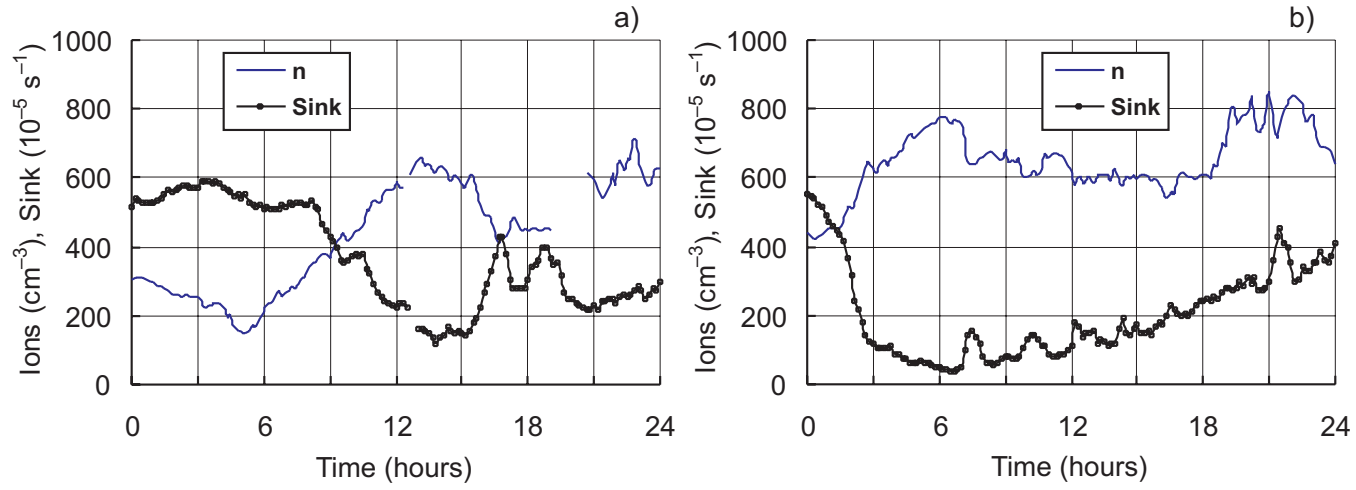

\section{$5,2749-2790,2005$}

\section{Air ions in boreal forest air}

U. Hõrrak et al.
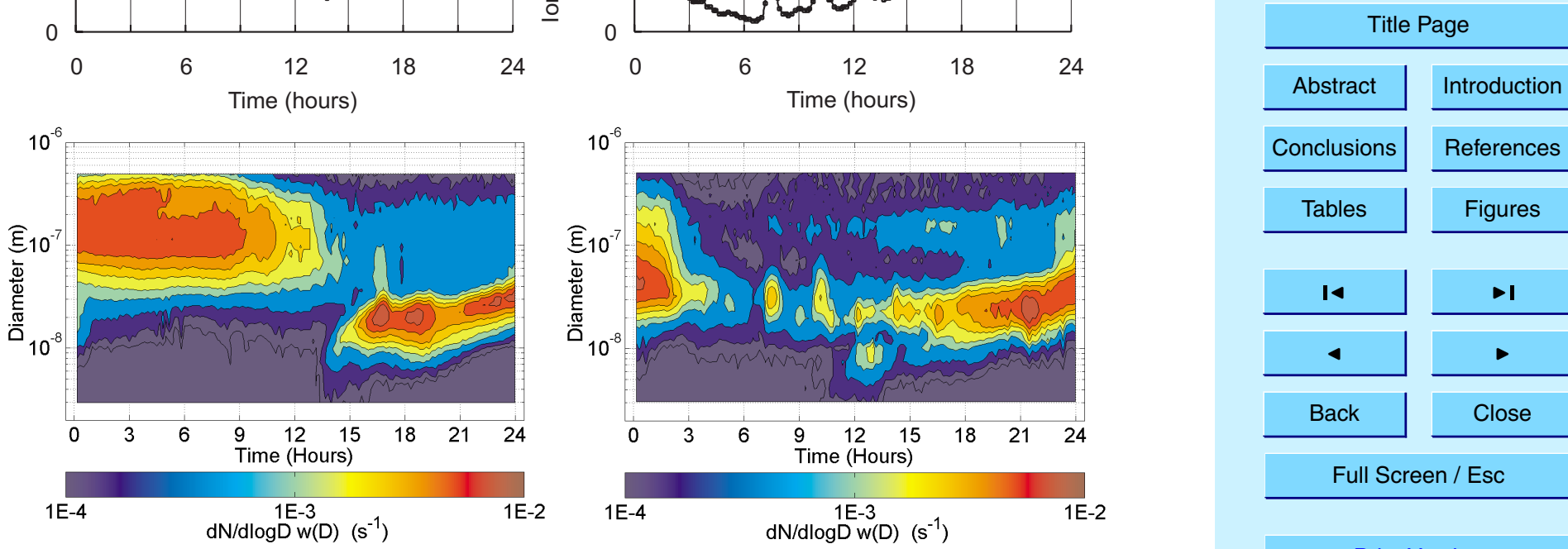

Fig. 7. Diurnal variation in the concentration of small ions $(n)$, ion sink $\left(S_{a}\right)$ and the size distribution of ion sink due to aerosol particles $(3-500 \mathrm{~nm})$ on 2 April (a; left) and 10 April 1999 (b; right) at Hyytiälä.

\section{Full Screen / Esc}

Print Version

Interactive Discussion

EGU 


\section{ACPD}
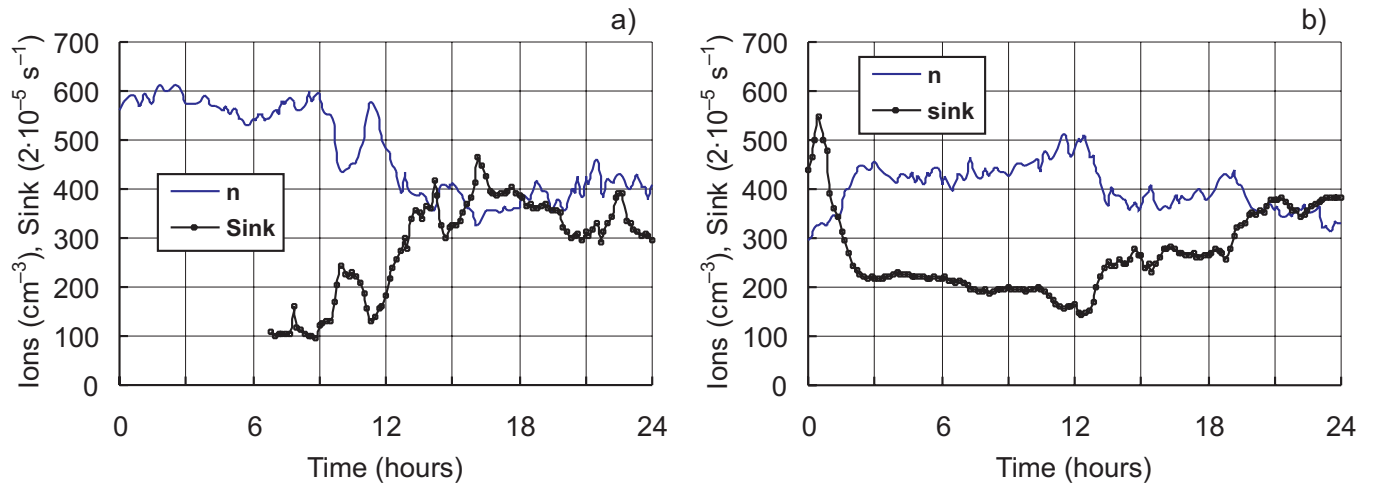

\section{$5,2749-2790,2005$}

\section{Air ions in boreal forest air}

U. Hõrrak et al.
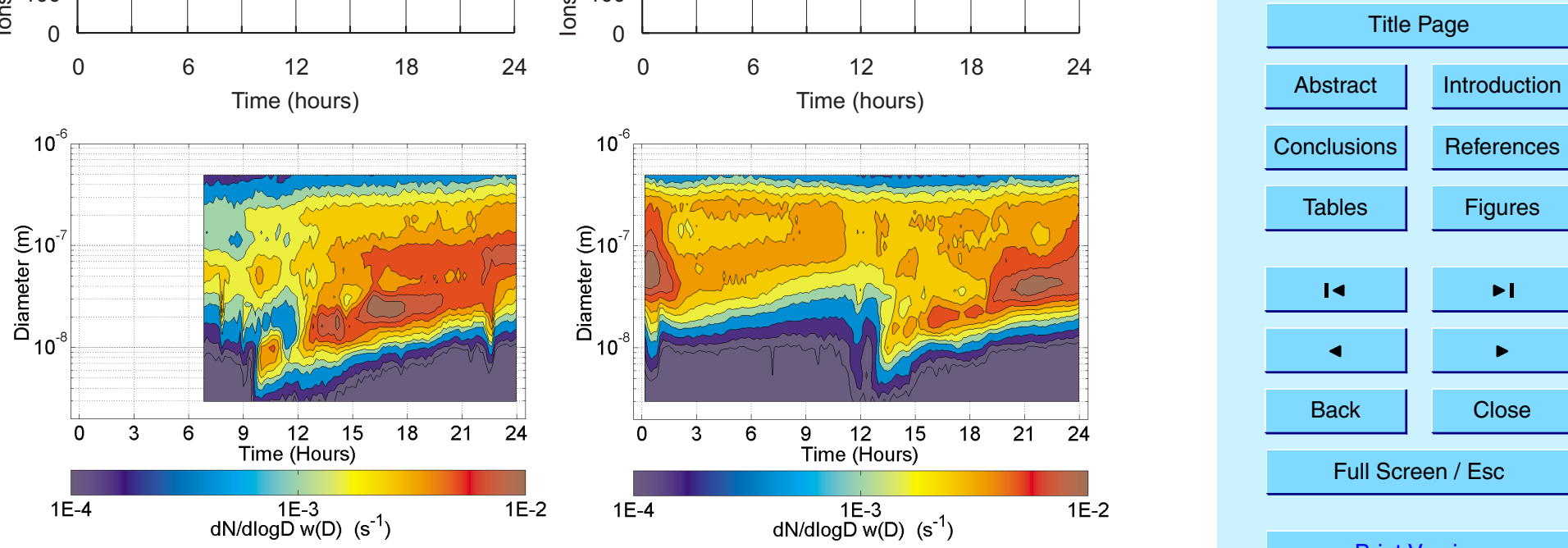

Fig. 8. Diurnal variation in the concentration of small ions $(n)$, ion sink $\left(S_{a}\right)$ and the size distribution of ion sink due to aerosol particles $(3-500 \mathrm{~nm})$ on 5 April (a; left) and 14 April 1999 (b; right) at Hyytiälä.

\section{Full Screen / Esc}

Print Version

Interactive Discussion

EGU 
a)

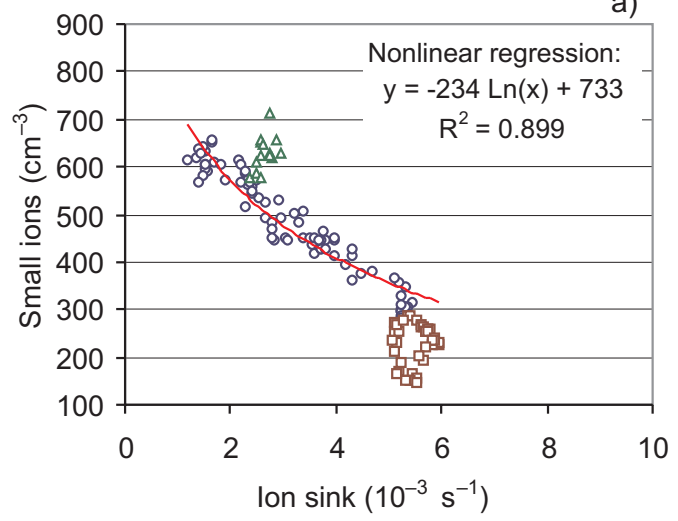

c)

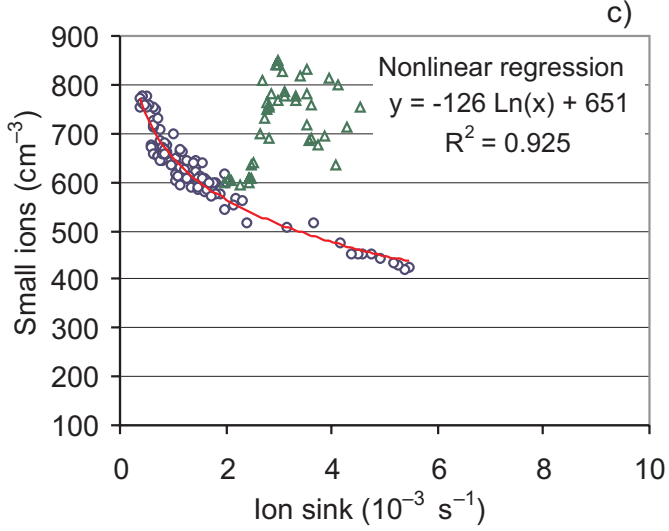

b)

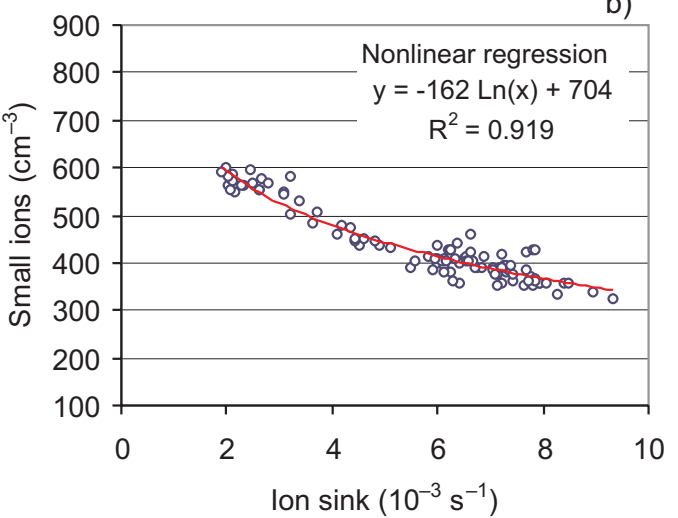

d)

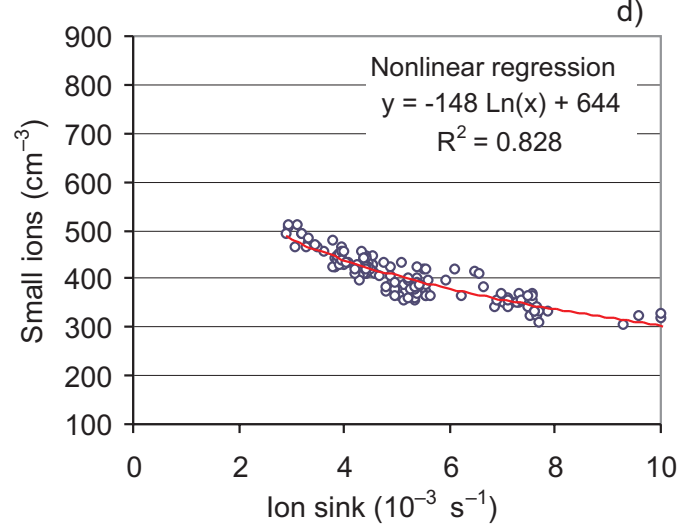

ACPD

5, 2749-2790, 2005

Air ions in boreal forest air

U. Hõrrak et al.

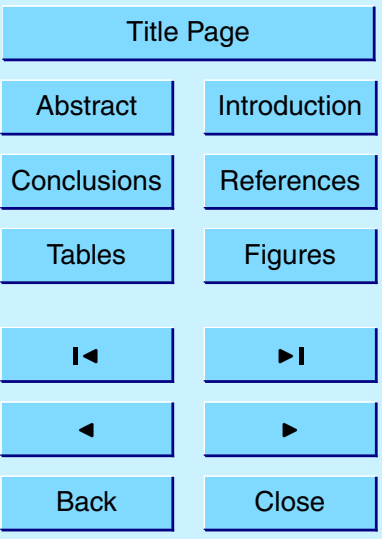

Full Screen / Esc

Print Version

Interactive Discussion

Fig. 9. Scatterplot between the small ion concentration and ion sink on 2 April (a), 5 April (b), 14 April (c) and 10 April 1999 (d) at Hyytiälä station. Specific data points: squares ( $\square$ ) correspond to the fog event; triangles $(\Delta)$ correspond to the period of weak wind less than $0.2 \mathrm{~m} \mathrm{~s}^{-1}$. Specific data points have been excluded from the regression analysis. 